\title{
Nonlinear Flow Behavior in Packed Beds of Natural and Variably Graded Granular Materials
}

\author{
J. H. van Lopik ${ }^{1,3} \cdot$ L. Zazai ${ }^{2}$ N. Hartog ${ }^{1,3} \cdot$ R. J. Schotting ${ }^{1}$
}

Received: 17 June 2019 / Accepted: 27 November 2019 / Published online: 10 December 2019

(c) The Author(s) 2019

\begin{abstract}
Under certain flow conditions, fluid flow through porous media starts to deviate from the linear relationship between flow rate and hydraulic gradient. At such flow conditions, Darcy's law for laminar flow can no longer be assumed and nonlinear relationships are required to predict flow in the Forchheimer regime. To date, most of the nonlinear flow behavior data is obtained from flow experiments on packed beds of uniformly graded granular materials $\left(C_{\mathrm{u}}=d_{60} / d_{10}<2\right)$ with various average grain sizes, ranging from sands to cobbles. However, natural deposits of sand and gravel in the subsurface could have a wide variety of grain size distributions. Therefore, in the present study we investigated the impact of variable grain size distributions on the extent of nonlinear flow behavior through 18 different packed beds of natural sand and gravel deposits, as well as composite filter sand and gravel mixtures within the investigated range of uniformity $\left(2.0<C_{\mathrm{u}}<17.35\right)$ and porosity values $(0.23<n<0.36)$. Increased flow resistance is observed for the sand and gravel with high $C_{\mathrm{u}}$ values and low porosity values. The present study shows that for granular material with wider grain size distributions $\left(C_{\mathrm{u}}>2\right)$, the $d_{10}$ instead of the average grain size $\left(d_{50}\right)$ as characteristic pore length should be used. Ergun constants $A$ and $B$ with values of 63.1 and 1.72, respectively, resulted in a reasonable prediction of the Forchheimer coefficients for the investigated granular materials.
\end{abstract}

Keywords Variably graded granular material · Porosity · Coefficient of uniformity · Forchheimer equation · Nonlinear flow

\section{Introduction}

In general, flow processes in groundwater flow studies can be described by Darcy's law (1856):

\section{J. H. van Lopik}

Jan.van.Lopik@kwrwater.nl

1 Department of Earth Sciences, Hydrogeology Group, Utrecht University, Princetonlaan 8, 3584 CB Utrecht, The Netherlands

2 Master Program Teacher Physics, Hogeschool Utrecht, Padualaan 97, 3584 CH Utrecht, The Netherlands

3 KWR Water Cycle Research Institute, Groningenhaven 7, 3433 PE Nieuwegein, The Netherlands 


$$
i=-\frac{1}{K} q
$$

where $i[\mathrm{~m} / \mathrm{m}]$ is the hydraulic gradient, $K[\mathrm{~m} / \mathrm{s}]$ is the hydraulic conductivity, and $q[\mathrm{~m} / \mathrm{s}]$ is the specific discharge. At higher flow velocities in porous media, Darcy's law does not hold and the specific discharge starts to deviate from the linear Darcy's law after a certain threshold hydraulic gradient. Forchheimer (1901) proposed alternative equations to describe post-Darcian flow behavior, which can be categorized in the two-term, the threeterm and the power law (Bear 1972). Theoretical base for the different Forchheimer forms in a particular porous medium for given flow velocity ranges are provided in the literature (e.g., Hassanizadeh and Gray 1987; Whitaker 1996; Skjetne and Auriault 1999; Chen et al. 2001; Adler et al. 2013). The second-order polynomial two-term Forchheimer equation is widely used for groundwater flow problems and describes the nonlinear behavior with adding a quadratic term to Darcy's law:

$$
i=-a q-b q^{2}
$$

where $a[\mathrm{~s} / \mathrm{m}]$ is a parameter equal to the reciprocal of the hydraulic conductivity (i.e., $a=1 / K)$ and $b\left[\mathrm{~s}^{2} / \mathrm{m}^{2}\right]$ is the empirical Forchheimer coefficient. The onset of nonlinear laminar flow behavior is ascribed to different mechanisms of energy dissipation (e.g., Hassanizadeh and Gray 1987; Ma and Ruth 1993; Lage 1998; Nield 2000; Chen et al. 2001; Panfilov and Fourar 2006).

Ergun (1952) extended the Kozeny-Carman relationship to relate the Forchheimer coefficients to the grain size and porosity of a porous medium by:

$$
i=-A \frac{(1-n)^{2} v}{g n^{3} d^{2}} q-B \frac{(1-n)}{g n^{3} d} q^{2}
$$

where $g\left[\mathrm{~m} / \mathrm{s}^{2}\right]$ is the acceleration due to gravity, $d[\mathrm{~m}]$ is the characteristic pore length by means of the particle diameter, $v\left[\mathrm{~m}^{2} / \mathrm{s}\right]$ is the kinematic viscosity of the fluid, $n[-]$ is the porosity, $A$ is the Ergun constant that equals 150 and $B$ is the Ergun constant that equals 1.75 (Ergun 1952). Many variations on the Ergun relation for different kinds of porous media and flow regimes are given in the literature (e.g., Engelund 1953; Irmay 1964; MacDonald et al. 1979; Du Plessis 1994; Sedghi-Asl and Rahimi 2011; Erdim et al. 2015; Guo et al. 2019).

The understanding of high-velocity flows over steep hydraulic gradients through hydrogeological formations is important for a broad range of large scale flow problems. Such flow problems are, for example, the flow through waste deposits $\left(d_{10}=10 \mathrm{~mm}\right)$ up to velocities of $10 \mathrm{~m} / \mathrm{s}$ (Greenly and Joy 1996), transient flow due to steep head gradients by sudden head rise or drawdown in aquifers and constructed wetlands (Moutsopoulos and Tsihrintzis 2005; Moutsopoulos 2007), as well as flow through landfill caps or leachate collection systems up to velocities of $0.6 \mathrm{~m} / \mathrm{s}$ (Bordier and Zimmer 2000). Moreover, in many groundwater applications the efficiency of injection/abstraction wells is affected by nonlinear head losses since flow velocities increase due to the divergence/convergence of flow lines in the vicinity of wells (e.g., Basak 1978; Mathias and Todman 2010; Yeh and Chang 2013; Wen et al. 2013; Houben 2015; Mathias and Moutsopoulos 2016). In general, nonlinear head losses will occur in the gravel pack while flow in the aquifer can be considered as linear Darcian flow for common well designs (Houben, 2015). However, for naturally developed wells with a well screen in direct contact with the naturally developed aquifer material, steep hydraulic gradients and nonlinear head losses occur in the aquifer 
material itself. Houben et al. (2018) stated that reduction in porosity in the gravel pack by clogging could have a significant influence on nonlinear head losses during well operation. Besides well hydraulics, the influence of nonlinear flow behavior through natural granular materials is important for analyzing slug tests in highly permeable sandy aquifers of $K>50 \mathrm{~m} / \mathrm{d}$ (McElwee and Zenner 1998), as well as for analyzing packer test data (e.g., Yamada et al. 2005).

To date, a broad range of experimental studies on nonlinear flow behavior in different kind of porous media is available in the literature. Experimental datasets on nonlinear flow behavior through various kinds of packed beds of granular material show that the Forchheimer equation (Eq. 2) can be used to predict flow over a wide range flow velocities (e.g., Moutsopoulos et al. 2009; Sedghi-Asl et al. 2014; Ferdos et al. 2015; Salahi et al. 2015; Li et al. 2017; van Lopik et al. 2017). Most literature provide data on flow through packed beds of coarser granular materials, such as gravels and cobbles with an uniform grain size distribution (e.g., Sidiropoulou et al. 2007; Moutsopoulos et al. 2009; Sedghi-Asl et al. 2014; Salahi et al. 2015). The experimental studies of van Lopik et al. (2017) and Li et al. (2019) focus on small variations in gradation by adding only a small amount of both finer and coarser material to a given uniformly graded reference sand.

In contrast, however, for natural sand and gravel deposits the grain size distribution is usually non-uniformly graded. Only a limited amount of studies provides information about both the grain size distribution of the material and the nonlinear flow behavior through non-uniformly graded granular materials (e.g., Yamada et al. 2005; Dan et al. 2016; Wang et al. 2019). Hence, the understanding of nonlinear flow behavior through packed beds of graded natural sand and gravel deposits requires a much broader experimental dataset than provided in the present literature.

The aim of this study is to provide insight in the differences in nonlinear flow behavior through packed beds of a wide range of graded sand and gravel types. Therefore, in the present study the effect of nonlinear flow behavior through packed beds of granular material with wider grain size distribution and lower corresponding porosities is investigated. This is done by experimental tests on packed beds of natural sands and gravels from unconsolidated aquifers in the Netherlands and Germany, as well as artificial composite mixtures of filter sands and gravels considering a broad range of grain size distributions and porosities at a given reference average grain size $\left(d_{50}\right)$ and compaction grade. The dataset of the present study on nonlinear flow behavior through packed beds of variably graded granular material is compared to the existing datasets in the literature on uniformly graded granular material. This is done to obtain insight in the difference in nonlinear flow behavior between these types of granular materials.

\section{Experimental Data from Previous Studies}

A wide variety of experimental studies on nonlinear flow behavior through packed beds of all kinds of material is provided in the literature. Investigation of fluid/gas flow through packed beds of artificial compounds is done, such as cubes, cylinders, ellipsoids, fibers, cubic arrays of spheres, as well rounded spheres of glass or metal (e.g., MacDonald et al. 1979; Sidiropoulou et al. 2007; Allen et al. 2013; Huang et al. 2013; Bağci et al. 2014; Erdim et al. 2015). Besides artificial compounds, the literature provides a broad dataset on nonlinear flow behavior through all kinds of granular material, ranging from sand to cobbles. In the present study, the selection of the experimental data on nonlinear flow behavior 
through granular material in Table 1 is considered in order to compare the results between uniformly graded material and non-uniformly graded material.

Most studies have focused on flow through packed beds with uniform-sized grains (e.g., Sedghi-Asl et al. 2014; Salahi et al. 2015; Li et al. 2017). For the experimental studies on packed beds of granular material with wider grain size distributions, the data provides information on gradation by means of the coefficient of uniformity $C_{\mathrm{u}}[-]$ and the coefficient of curvature $C_{\mathrm{c}}[-]$ (e.g., Yamada et al. 2005):

$$
C_{U}=\frac{d_{60}}{d_{10}}
$$

and

$$
C_{C}=\frac{\left(d_{30}\right)^{2}}{d_{10} * d_{60}}
$$

In the studies of van Lopik et al. (2017) and Li et al. (2019), mixtures of granular material were used to obtain slightly more well-graded composite sands. Wider grain size distributions (higher $C_{\mathrm{u}}$ values) for a material at a given average grain size and porosity resulted in increased flow resistance and, hence, increased Forchheimer coefficients $a$ and $b$.

Besides gradation, the compaction grade (e.g., Dan et al. 2016; Banerjee et al. 2018) and the grain shape (e.g., Allen et al. 2013; Salahi et al. 2015) of the granular material has a significant effect on nonlinear flow behavior. Packed beds of angular grains resulted in increased flow resistance compared to rounded grains (Salahi et al. 2015). The influence of particle shape is also shown for randomly packed beds of cubes and cylinders instead of rounded spheres with a diameter of $2.7 \mathrm{~mm}$ (Allen et al. 2013). The flow resistance for such materials is drastically increased, resulting in the highest Forchheimer coefficients for the packed beds of cubes.

\section{Methods}

The experimental setup as shown in Fig. 1 is used for the one-dimensional packed column flow experiments. This setup is similar to the one used for the nonlinear flow experiments in the study of van Lopik et al. (2017) and consists of the following main components:

- The inlet and outlet compartment (1 and 2). During the flow experiments the pressure at the inlet compartment (1) is measured, while at the outlet compartment (2) the hydraulic head is fixed at $0.505 \mathrm{~m}$.

- The packed column (length is $0.507 \mathrm{~m}$, diameter is $0.098 \mathrm{~m}$ ) with the porous medium (3). Besides the inlet and outlet compartment, the pressure is monitored at $0.13,0.26$, and $0.38 \mathrm{~m}$ distance from the inlet with a BD Sensors pressure transmitter combined with the BD Sensors PA 430 display (4). The interpolation of the measured water heads at a given specific flow rate resulted in a linear hydraulic head gradient over the entire column length for all experiments.

- The circulation tank of $1 \mathrm{~m}^{3}$ with a submersible pump (5). Due to pumping, water was significantly heated during the experimental process. Therefore, the water temperature is measured in the outlet compartment (6) and cold water is added to the circulation tank during the flow experiment to ensure constant water temperature at $20{ }^{\circ} \mathrm{C}$ 


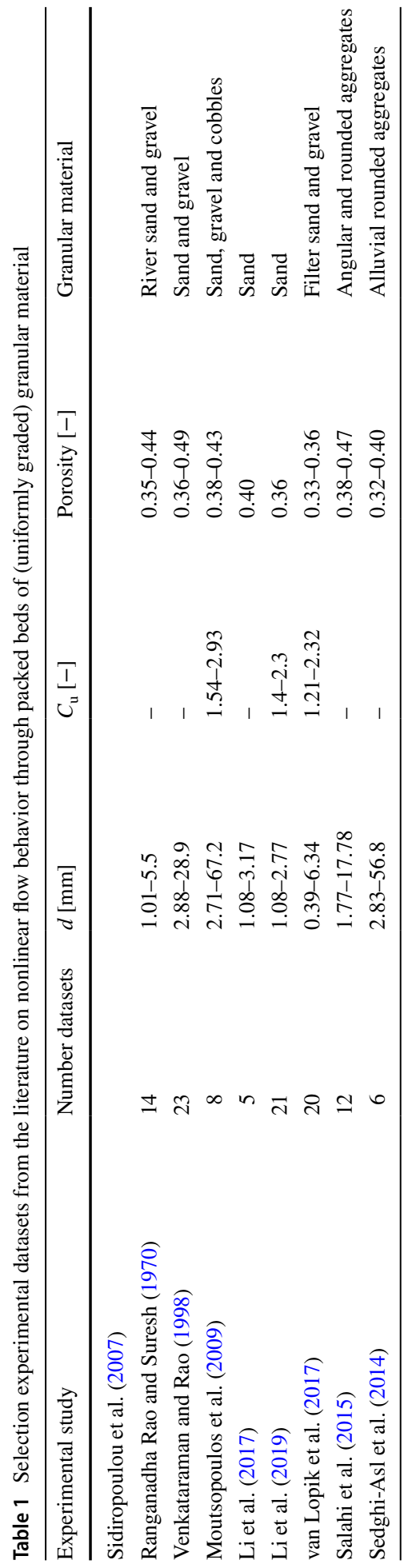




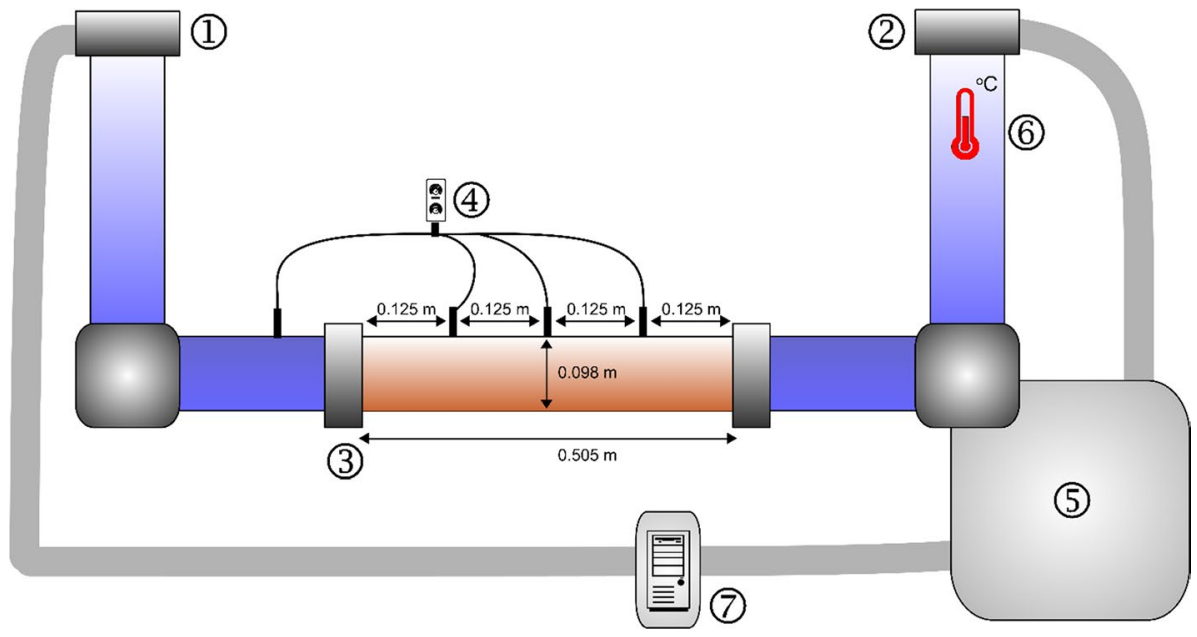

Fig. 1 Schematic overview of the experimental setup: (1) inlet compartment, (2) outlet compartment, (3) packed column with porous medium, (4) pressure sensor, (5) circulating tank with pump, (6) thermometer and (7) volumetric flow meter

$\left( \pm 0.5^{\circ} \mathrm{C}\right)$ and constant dynamic viscosity of approximately $0.001 \mathrm{~Pa}$. The volumetric flow rate $Q\left[\mathrm{~m}^{3} / \mathrm{h}\right]$ is measured using a SVM F2 Energy Meter (7). At a given hydraulic gradient, the flow rate is determined after steady-state flow conditions were obtained.

\subsection{Characteristics of Investigated Granular Material}

Two different sets of porous media are investigated in the present study:

- Natural sand and gravel deposits obtained from drilling samples from aquifers in the Netherlands (M.1-3) and Germany (W.1-2).

- Composite mixtures of sand and gravel obtained by mixing of selected portions of different uniformly graded filter sands and gravels (S.1-3).

\subsubsection{Natural Sand and Gravel Deposit Samples}

All natural sand and gravel samples are obtained from drilling cores in aquifers. The natural sands M.1-3 are obtained by cable tool drilling at a location near the Münsterlaan at the Utrecht University Campus (the Netherlands). The samples are from a sandy unconsolidated aquifer and are fluvial Pleistocene deposits classified as Kreftenheye formation. The samples are obtained from two different drilling locations at only $12 \mathrm{~m}$ distance of each other. Sand sample M.1 is obtained at a depth of $12.50-14.50 \mathrm{mbgl}$. At the other location, the sampling depth is the same for M.2 (12.50-14.50 mbgl), while the depth is 9.50-10.50 mbgl for M.3. The natural sand W.1 and gravel W.2 are reverse-circulation drilling disturbed soil samples at depths of, respectively, 20-21 mbgl, and 19-20 mbgl. The samples are Pleistocene river terrace sediments obtained from a sandy unconsolidated heterogeneous-layered aquifer near Wyenhütte in Rheindahlen, about $10 \mathrm{~km}$ southwest of 
Mönchengladbach (Germany). The grain size distributions for the natural sand and gravel samples (M.1-3 and W.1-2) are obtained by sieve analysis using sieve sizes $0.063,0.125$, $0.25,0.355,0.5,0.71,1.0,2.0,5.3,8,16.0,22.6$ and $32.0 \mathrm{~mm}$.

\subsubsection{Composite Mixtures of Sand and Gravel}

Similar to the study of van Lopik et al. (2017), uniformly graded filter sands (with a $C_{\mathrm{u}}<1.5$ ) are mixed to obtain sand and gravel material with the desired gradation (see "Appendix 1" for the mass fraction mixing ratios of the filter sands). For the composite mixture samples with wider grain size distribution, the required gravel (grain sizes larger than $10 \mathrm{~mm}$ ) is obtained by selection at minimum grain sizes of 10, 15, 20 and $30 \mathrm{~mm}$. In the present study, the filter sands with an average grain size diameter of 1.0 (Sample 1), 1.5 (Sample 2) and $6.3 \mathrm{~mm}$ (Sample 3) are used as reference material. The reference samples 1, 2 and 3 are, respectively, samples 7, 9 and 11 in the dataset of van Lopik et al. (2017).

\subsubsection{Analyzation of the Granular Material}

The gradation for both kinds of materials is described by means of the coefficient of uniformity $C_{\mathrm{u}}$ and the coefficient of curvature $C_{\mathrm{c}}$ (Eqs. 4, 5). The porosity of each packed sample is determined by weighing the dry mass of granular sand or gravel in the column. The solid phase density of the sand and gravel used for the composite mixtures equals $2.66 \mathrm{~kg} / \mathrm{m}^{3}$ (data by FILCOM, Papendrecht, the Netherlands). Moreover, the porosity of each material was determined by measuring the used granular material volume from the packed column under fully saturated conditions in a given water volume. Equal porosities are obtained for the composite mixtures of sand and gravel [Samples 1.(1-5), 2.(1-5) and 3.(1-3)] with above-mentioned methods. The characteristics of the natural as well as the composite mixtures of sand and gravel are given in Table 2.

Additionally, the grain shape properties of both the natural sand and composite sands are obtained using the CAMSIZER ${ }^{\circledR} \mathrm{P} 4$ (Retsch, Germany) image analysis technique (see “Appendix 2"). For all samples, the grain sizes in the range of 0.063-2.0 mm were selected in order to determine the grain shape of the sand. The grain shape properties of the used filter sands for the artificially mixed composite sands as well as for the natural deposit sands are similar. All investigated granular material is subangular-subrounded.

\subsection{Preparation Procedure for the Packed Columns}

Similar to the procedure in the study of van Lopik et al. (2017), the consistent packing method of Rietdijk et al. (2010) is used to obtain reproducible and homogenous packed porous media. To ensure homogeneous packing over the entire length of the column, small sand/gravel portions with the required mixture of fine and coarse material are carefully poured into the fully saturated column. The column is prepared, packed and installed under fully saturated conditions in a large container filled with water. In order to obtain the highest compaction grade, the deposited sand in the column is manually compressed throughout the packing process.

The consistent use of the Rietdijk et al. (2010) method resulted in the highest grain size density for a given sample (van Lopik et al. 2017). In Fig. 2, the effect of gradation on the porosity is shown for the samples listed in Table 2. For sand and gravels 
Table 2 The grain size distribution characterization and porosity values for all sand and gravel samples

\begin{tabular}{|c|c|c|c|c|c|c|c|c|}
\hline \multicolumn{2}{|c|}{ Sample } & \multirow{2}{*}{$\frac{d_{50}[\mathrm{~mm}]}{0.45}$} & \multirow{2}{*}{$\frac{d_{10}[\mathrm{~mm}]}{0.2}$} & \multirow{2}{*}{$\frac{d_{30}[\mathrm{~mm}]}{0.33}$} & \multirow{2}{*}{$\frac{d_{60}[\mathrm{~mm}]}{0.52}$} & \multirow{2}{*}{$\frac{C_{\mathrm{c}}}{1.05}$} & \multirow{2}{*}{$\frac{C_{\mathrm{u}}}{2.60}$} & \multirow{2}{*}{$\frac{n[-]}{0.328}$} \\
\hline M.1 & Natural sand: Münsterlaan & & & & & & & \\
\hline M.2 & Natural sand: Münsterlaan & 0.54 & 0.22 & 0.39 & 0.62 & 1.12 & 2.82 & 0.330 \\
\hline M.3 & Natural sand: Münsterlaan & 0.77 & 0.29 & 0.49 & 1.12 & 0.74 & 3.86 & 0.293 \\
\hline W.1 & Natural sand: Wyenhütte & 1.48 & 0.455 & 0.76 & 2.2 & 0.58 & 4.84 & 0.249 \\
\hline W.2 & Natural gravel: Wyenhütte & 9.5 & 0.95 & 4.1 & 12.4 & 1.43 & 13.05 & 0.246 \\
\hline S.1 & Filter sand: Filcom comp. & 1.05 & 0.89 & 0.98 & 1.08 & 1.01 & 1.30 & 0.348 \\
\hline 1.1 & Artificially mixed filter sand & 1.05 & 0.47 & 0.78 & 1.11 & 1.18 & 2.36 & 0.346 \\
\hline 1.2 & Artificially mixed filter sand & 1.05 & 0.39 & 0.63 & 1.31 & 0.78 & 3.36 & 0.337 \\
\hline 1.3 & Artificially mixed filter sand & 1.05 & 0.35 & 0.50 & 1.43 & 0.50 & 4.09 & 0.307 \\
\hline 1.4 & Artificially mixed filter sand & 1.05 & 0.35 & 0.50 & 1.55 & 0.46 & 4.43 & 0.285 \\
\hline 1.5 & Artificially mixed filter sand & 1.05 & 0.33 & 0.44 & 4.50 & 0.13 & 13.64 & 0.253 \\
\hline S. 2 & Filter sand: Filcom comp. & 1.50 & 1.16 & 1.34 & 1.58 & 0.98 & 1.36 & 0.358 \\
\hline 2.1 & Artificially mixed filter sand & 1.50 & 0.81 & 1.25 & 1.62 & 1.19 & 2.00 & 0.358 \\
\hline 2.2 & Artificially mixed filter sand & 1.50 & 0.60 & 0.97 & 1.73 & 0.91 & 2.88 & 0.334 \\
\hline 2.3 & Artificially mixed filter sand & 1.50 & 0.40 & 0.70 & 1.88 & 0.65 & 4.70 & 0.307 \\
\hline 2.4 & Artificially mixed filter sand & 1.50 & 0.40 & 0.70 & 2.63 & 0.47 & 6.58 & 0.265 \\
\hline 2.5 & Artificially mixed filter sand & 1.50 & 0.34 & 0.49 & 5.90 & 0.12 & 17.35 & 0.242 \\
\hline S.3 & Filter sand: Filcom comp. & 6.34 & 5.16 & 5.87 & 6.55 & 1.02 & 1.27 & 0.361 \\
\hline 3.1 & Artificially mixed filter sand & 6.34 & 1.84 & 4.85 & 6.86 & 1.86 & 3.73 & 0.324 \\
\hline 3.2 & Artificially mixed filter sand & 6.34 & 1.36 & 1.91 & 10.00 & 0.27 & 7.35 & 0.252 \\
\hline 3.3 & Artificially mixed filter sand & 6.34 & 1.18 & 1.47 & 14.55 & 0.13 & 12.33 & 0.227 \\
\hline
\end{tabular}

The samples S.1, S.2 and S.3 in italic are the reference sands obtained from dataset of van Lopik et al. (2017) (respectively, samples 7, 9 and 11 in their study)

Fig. 2 Relationship between the coefficient of uniformity $\left(C_{\mathrm{u}}\right)$ and the porosity values for all prepared column samples with the Rietdijk et al. (2010) packing method

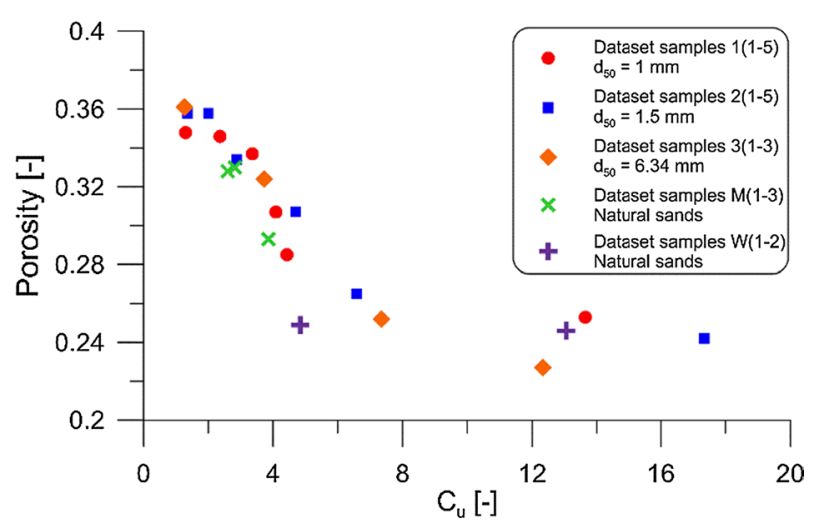

with wide grain size distributions (high $C_{\mathrm{u}}$ values), the fines tend to fill the void spaces between the larger sand particles, resulting in lower porosity values (Das 2008). For the relatively uniformly graded material $\left(C_{\mathrm{u}}<3\right)$, the porosity values are higher than 0.33 . 
The porosity is reduced for granular material samples with wider grain size distributions $\left(C_{\mathrm{u}}>6\right)$, resulting in porosity values lower than 0.27 .

\subsection{Ergun Friction Factor and Reynolds Number}

The Reynolds number is used to indicate whether fluid flow is laminar or turbulent. The most common definition of the Reynolds number is defined as (Bear 1972):

$$
\operatorname{Re}=\frac{\rho d q}{\mu}=\frac{\text { inertial forces }}{\text { viscous forces }}
$$

where $\rho\left[\mathrm{kg} / \mathrm{m}^{3}\right]$ is the fluid density and $\mu[\mathrm{kg} / \mathrm{m} \mathrm{s}]$ is the dynamic viscosity. In the present study, the onset of nonlinear flow behavior by means of a critical Reynolds number $\operatorname{Re}_{\mathrm{cr}}$ is defined as a significant nonlinear deviation in specific discharge of (>5\%) from Darcy's law.

For the Ergun equation (Eq. 3), the following form of the friction factor $f$ and Reynolds number $\operatorname{Re}_{p}$ is obtained:

$$
f=i \frac{g d}{q^{2}}\left(\frac{n^{3}}{1-n}\right) \text { and } \operatorname{Re}_{p}=\frac{\rho d q}{(1-n) \mu}=\frac{\operatorname{Re}}{1-n}
$$

Hence, the relation between friction factor $f$ and Reynolds number $\operatorname{Re}_{p}$ is given by:

$$
f=\frac{A}{\operatorname{Re}_{p}}+B
$$

where $A$ and $B$ are the Ergun constants (which are equal to 150 and 1.75 for the Ergun equation).

\subsection{Empirical Correlation for the Nonlinear Flow Forchheimer Coefficient}

The Ergun equation (Eq. 3) is the extended form of the Kozeny-Carman equation for nonlinear flow behavior and can be used to estimate both the Forchheimer coefficient $a$ and $b$ based on the average grain size diameter and porosity. In the literature, a wide variety of empirical relationships are provided which correlates the Forchheimer $b$ coefficient to the intrinsic permeability $(k)$, porosity and tortuosity (see Table 3 ).

Carman (1937) already recognized that porous media exists of complex pore structures, and streamlines are far from being completely straight and parallel to each other. This effect can be described by a dimensionless parameter $\tau$ called the hydraulic tortuosity (Bear 1972):

Table 3 Different correlation forms for the Forchheimer coefficient $\beta$, where $\beta=b g$

\begin{tabular}{lll}
\hline Correlation form for $\beta\left[\mathrm{cm}^{-1}\right]$ & Units $k$ & Literature \\
\hline$\beta=0.005 k^{-1 / 2} n^{-\frac{11}{2}}$ & $\mathrm{~cm}^{2}$ & Geertsma (1974) \\
$\beta=1.82 * 10^{8} k^{-5 / 4} n^{-\frac{3}{4}}$ & $\mathrm{mD}$ & Janicek and Katz (1955) \\
$\beta=2.94 * 10^{7} \frac{\tau}{k n}$ & $\mathrm{mD}$ & Liu et al. (1995) \\
$\beta=1.55 * 10^{4} k^{-0.98} n^{-0.29} \tau^{3.35}$ & $\mathrm{D}$ & Thauvin and Mohanty (1998) \\
\hline
\end{tabular}




$$
\tau=\frac{L}{L_{\mathrm{e}}}
$$

where $L[\mathrm{~m}]$ is the straight line length that connects the two ends of the tortuous tube of length $L_{\mathrm{e}}[\mathrm{m}]$. Tortuosity is difficult to measure and hence, this parameter is less practical than porous media properties such as grain size and porosity. A broad range of empirical tortuosity equations exists for simpler pore geometries, while the available information in the literature on tortuosity for granular material that consists of mixed particle beds is scarce (e.g., Mota et al. 2001; Ghanbarian et al. 2013). Mota et al. (2001) proposed an empirical tortuosity-porosity power law for binary mixtures of spherical particles:

$$
\tau=n^{-0.4}
$$

In the present study, Eq. (10) is used to investigate if the correlation forms for $\beta$ of Liu et al. (1995) and Thauvin and Mohanty (1998) with the tortuosity model of Mota et al. (2001) work for the investigated non-uniformly graded granular material.

\section{Results}

In the present study, a nonlinear relationship between the hydraulic gradient $i$ and the specific discharge $q$ is found for the natural sand and gravel samples [M.(1-3) and W.(1-2)], as well as for the composite mixture samples (S.1-3) (Figs. 3, 4, 5, 6, 7). Forchheimer coefficients are determined by fitting the second-order polynomial function (Eq. 3) over the specific discharges and corresponding hydraulic gradients. The total amount of realizations for the samples ranges between 25 and 33. Excellent Forchheimer fits were obtained for all samples $\left(R^{2}>0.99\right)$. The Forchheimer coefficients $a$ and $b$ are listed in Table 4 for the natural sand and gravel samples, as well as for the composite mixture samples. In the present study, the determined critical Reynolds numbers range between 2.17 and 12.5. This is in line with the values of 1-15 suggested in the literature (Bear 1972; Hassanizadeh and Gray 1987; Ma and Ruth 1993; Comiti et al. 2000).
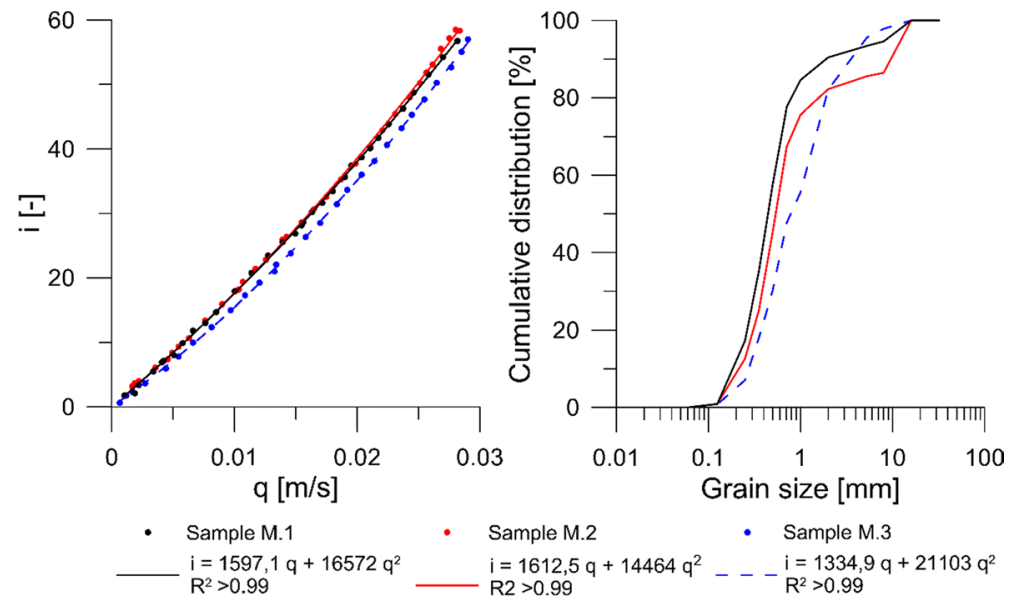

Fig. 3 Nonlinear relationships between the hydraulic gradient and the specific discharge and the grain size distributions for M.1-3 

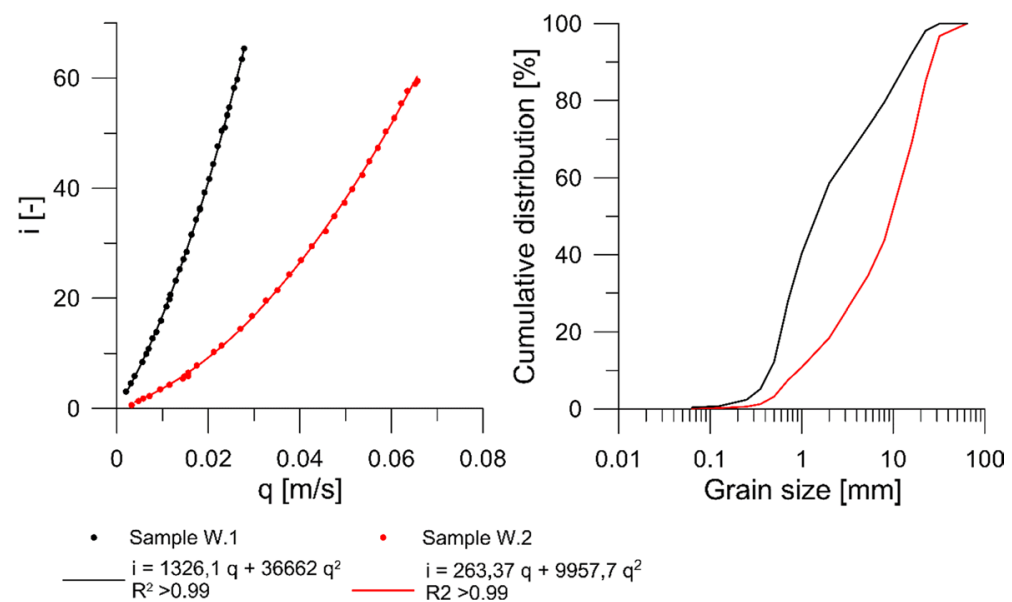

Fig. 4 Nonlinear relationships between the hydraulic gradient and the specific discharge and the grain size distributions for W.1-2
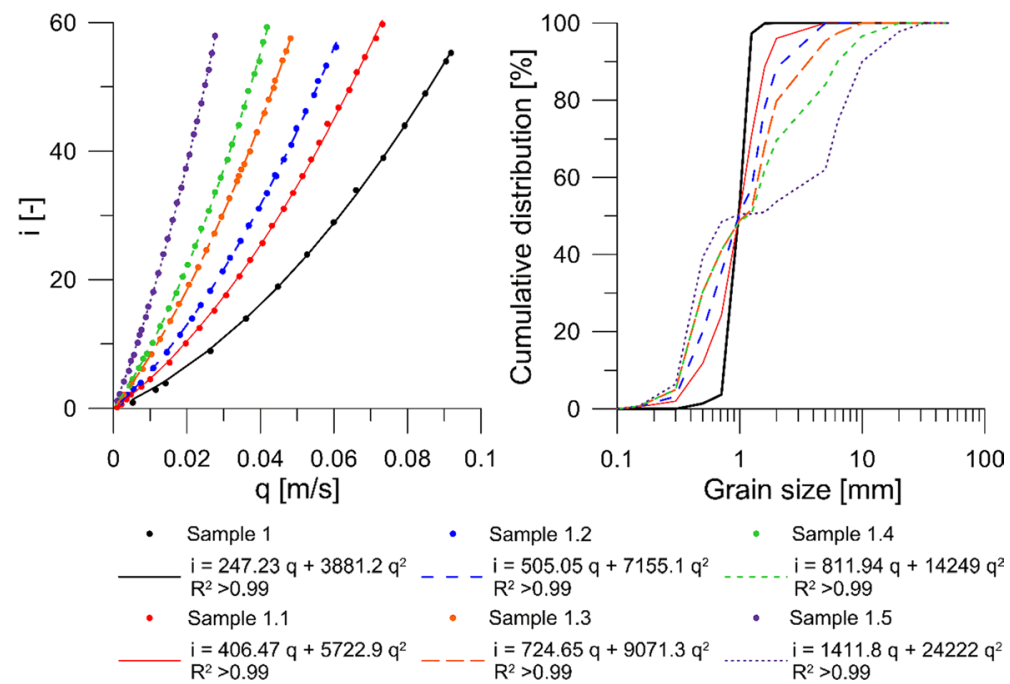

Fig. 5 Nonlinear relationships between the hydraulic gradient and the specific discharge and the grain size distributions for S.1.1-5

The measured ranges of $\mathrm{Re}_{\min }-\mathrm{Re}_{\max }$ for the packed column experiments on the natural sand and gravel samples are shown in Table 4. For the sand samples from the Münsterlaan (M.1-3), multiple data points are in the Darcy regime before flow is increased above the critical Reynolds number $\mathrm{Re}_{\mathrm{cr}}$ and hence, the onset of nonlinear flow is observed (respectively, 7, 5 and 3 datapoints for samples M.1, M.2 and M.3). 

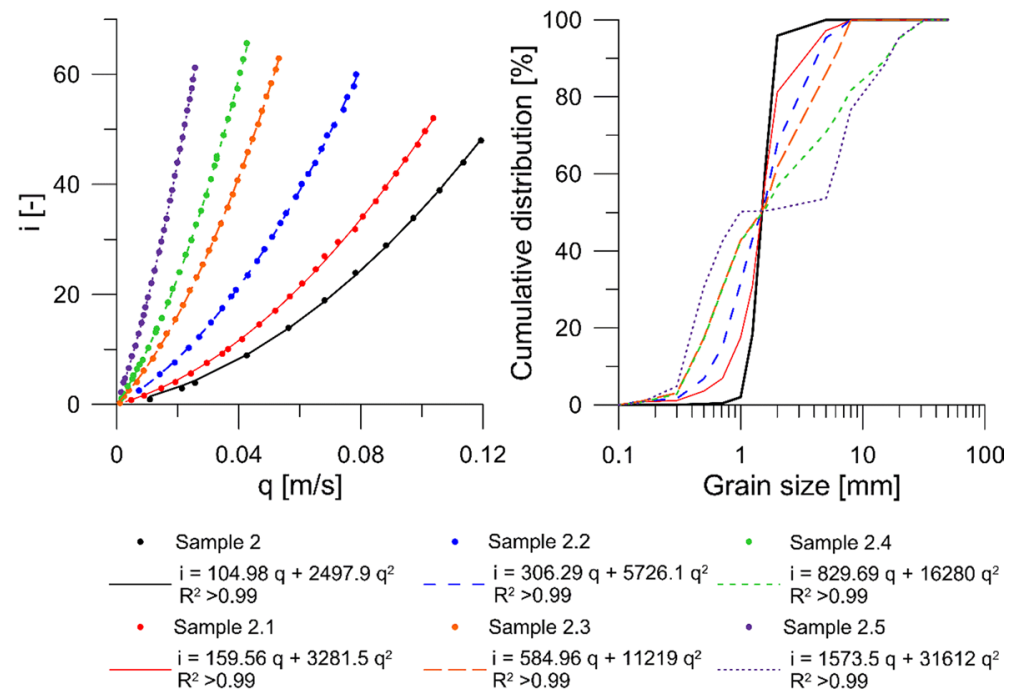

Fig. 6 Nonlinear relationships between the hydraulic gradient and the specific discharge and the grain size distributions for S2.1-5
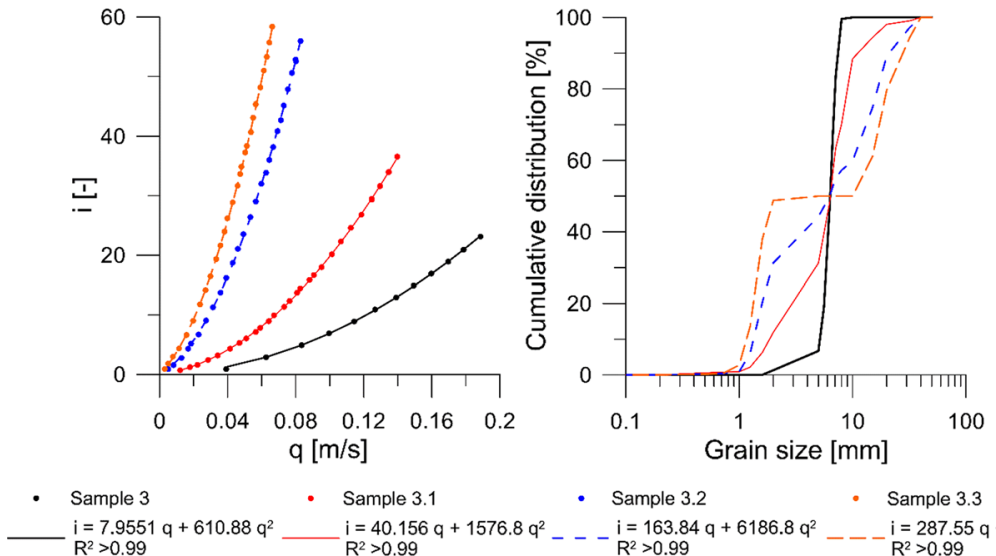

- Sample 3.1

- $\quad$ Sample 3.2

$i=163.84 q+6186.8 q^{2}$
$R^{2}>0.99$

- Sample 3.3

$=7.955$
$R^{2}>0.99$ $\begin{aligned} i & =40.156 \\ R^{2} & >0.99\end{aligned}$ $i=287.55 q+8941.1 q^{2}$

Fig. 7 Nonlinear relationships between the hydraulic gradient and the specific discharge and the grain size distributions for S.3.1-3

For the composite mixtures, multiple datapoints are measured in the Darcy regime for sample S.1(1-5) and S.2(3-5). The measured datapoints are solely in the nonlinear flow regime for the remaining composite mixtures and the samples from Wyenhütte W.(1-2). 


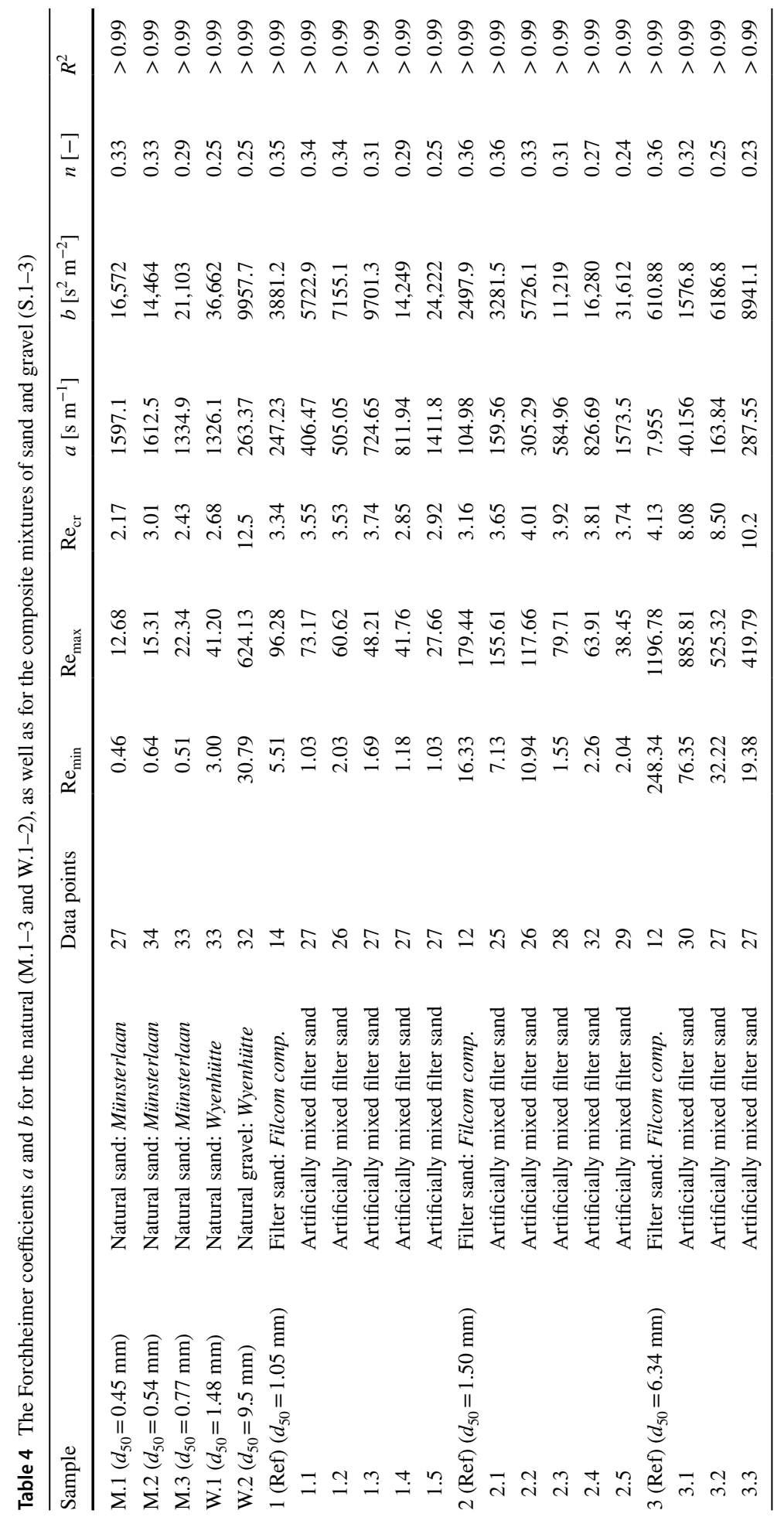




\subsection{Nonlinear Flow in Natural Sands and Gravels}

The same nonlinear flow behavior characteristics are observed for the samples M.1 and M.2 with approximately similar gradations, average grain sizes and porosity values. Compared to M.(1-2), the samples M.3 and W.1 have a wider grain size distribution (with $C_{\mathrm{u}}$ values of 3.86, and 4.84) and lower porosity values. The flow resistance was reduced for these samples with a higher average grain size, which resulted in lower Forchheimer coefficients $a$ of 1334.9 (M.3) and $1326.1 \mathrm{~s} / \mathrm{m}$ (W.1) compared to the values obtained for samples M.1-2 (Table 4). However, the Forchheimer coefficients $b$ for these samples are, respectively, a factor 1.5 (sample M.3) and 2.5 (sample W.1) higher than for sample M.2. For these samples, reduced porosity values (up to 0.25 ) due to wider grain size distributions resulted in significantly higher coefficients $b$, while only a small difference is observed between the coefficients $a$.

(a)

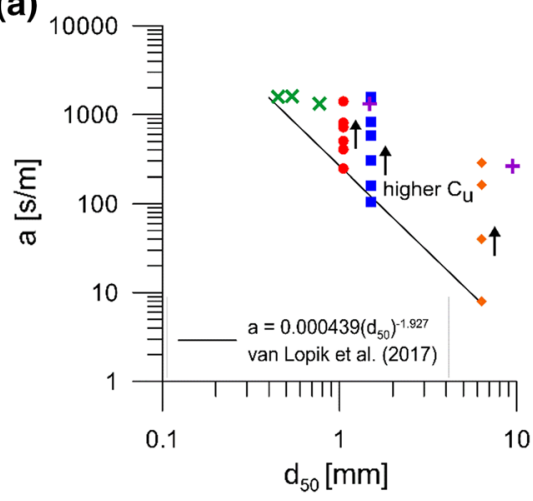

(c)

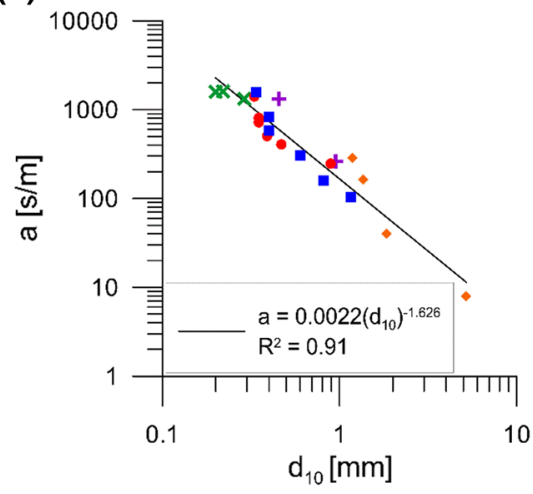

- Dataset samples 1(1-5) Dataset samples 2(1-5) (b)

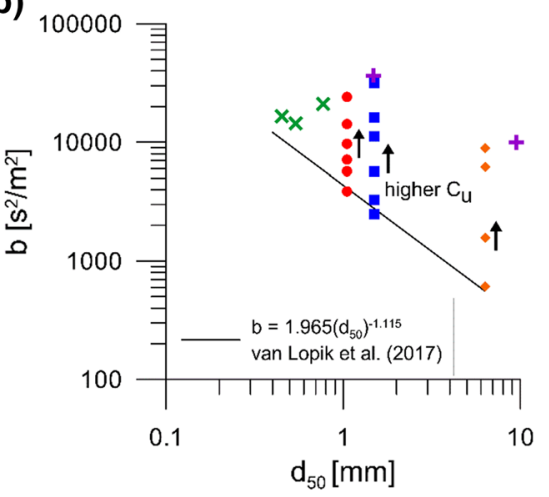

(d)

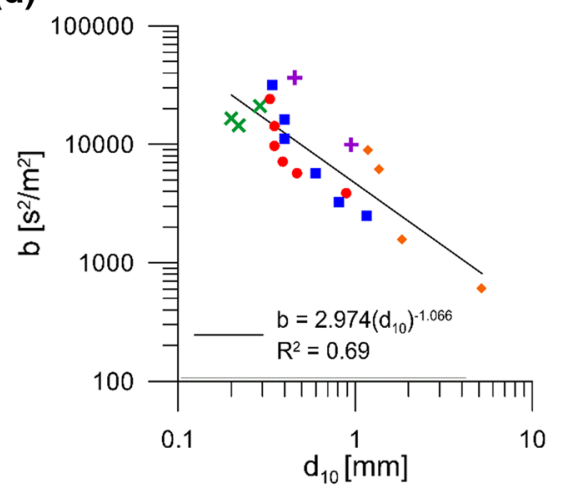

Fig. 8 a Relationship between the median grain size $\left(d_{50}\right)$ and Forchheimer coefficient $a$, as well as for $\mathbf{b}$ Forchheimer coefficient $b$, for the investigated sands. The increase in flow resistance for the sands with a higher $C_{\mathrm{u}}$ value is also indicated. c Relationship between the grain size $\left(d_{10}\right)$ and Forchheimer coefficient $a$, as well as for $\mathbf{d}$ Forchheimer coefficient $b$, for the investigated sands. Note that the shown relationships between the grain size and Forchheimer coefficients are calculated based on $d$ [units in $\mathrm{m}$ ] 


\subsection{Nonlinear Flow in the Composite Mixtures of Sand and Gravel}

The results show that gradation of a granular material has a large impact on nonlinear flow behavior (Figs. 5, 6, 7). For all tested composite mixture samples, a wider grain size distribution (i.e., increased $C_{\mathrm{u}}$ value) resulted in increased flow resistance with respect to the uniformly graded reference sand. This results in a poor correlation between the average grain size $d_{50}$ and the Forchheimer coefficients $a$ and $b$ (Fig. 8a-b). Using the $d_{10}$ as characteristic poor length, the correlation is significantly improved (Fig. 8c-d).

The $d_{30}$ is decreased by a factor of 0.80 and 0.64 with respect to the reference sample S.1 for, respectively, S.1.1 and S.1.2 (Table 2). Consequently, this results, respectively, in increased coefficients $a$ by a factor of 1.64 and 2.04, as well as increased coefficients $b$ by a factor of 1.47 and 1.84 (Table 4 ). The porosity was only slightly reduced to a value of 0.34 , compared to the value of 0.35 for the reference sample S.1. For S.1.5, the $d_{30}$ is decreased by a factor of 0.44 with respect to reference sample S.1. This resulted in an increase by a factor up to 5.71 for coefficient $a$ and up to 6.24 for coefficient $b$. In this case, the porosity was significantly lower than the reference sample with a value of 0.25 . Similar trends are also observed for the composite mixtures dataset S.2.(1-5). For the composite gravel S.3.3, the relative increase in flow resistance, and hence Forchheimer coefficients $a$ and $b$, compared to its reference sample S.3 was the highest of all samples with increases by a factor of 36.1 and 14.6, respectively.

Equal amounts of finer material were used for the samples S.1.3 and S.1.4 (Table 2 and Fig. 5). Composite mixture S.1.4 shows a relative increase in coarser material (i.e., tailing in the grain size distribution) with respect to S.1.3, which resulted in a porosity of 0.29 for S.1.4 instead of the 0.31 for S.1.3. Consequently, for S.1.4 the coefficient $a$ is increased by a factor of 1.43 and the coefficient $b$ is increased by a factor of 1.36 compared to the coefficients of S.1.3. A similar trend is observed for the composite mixtures S.2.3 and S.2.4, where also an equal amount of fine material was used (at $d_{30}$ of $0.7 \mathrm{~mm}$ ). In this case, the porosity was reduced to 0.27 for S.2.4, compared to a value of 0.31 for S.2.3, and coefficients $a$ and $b$ were increased by a factor of 1.41 and 1.45 , respectively.

\subsection{Ergun Constants for Granular Material}

In the present study, we have used the Ergun form of the friction factor (Eqs. 7, 8) to analyze the dataset from the literature (see Table 1), as well as the dataset from the present study on non-uniformly graded material (Fig. 9). For the characteristic pore length, the grain size $d_{50}$ was used to calculate the friction factor $f$ and $\operatorname{Re}_{p}$. Van Lopik et al. (2017) obtained the following relationship for the friction factor on their dataset of 20 different uniformly graded filter sands and gravels $\left(C_{\mathrm{u}}<2\right)$ :

$$
f=\frac{233.5}{\operatorname{Re}_{p}}+2.88 ; \quad \text { for } d_{50} \text { and } C_{u}<2
$$

Similarly, a relationship can be obtained from the results from present study:

$$
f=\frac{498.7}{\operatorname{Re}_{p}}+5.03 ; \quad \text { for } d_{50} \text { and } C u>2
$$

For the present study, a poor relationship between friction factor and Reynolds number is obtained for the entire dataset of the present study while using $d_{50}$ as characteristic pore 
(a)

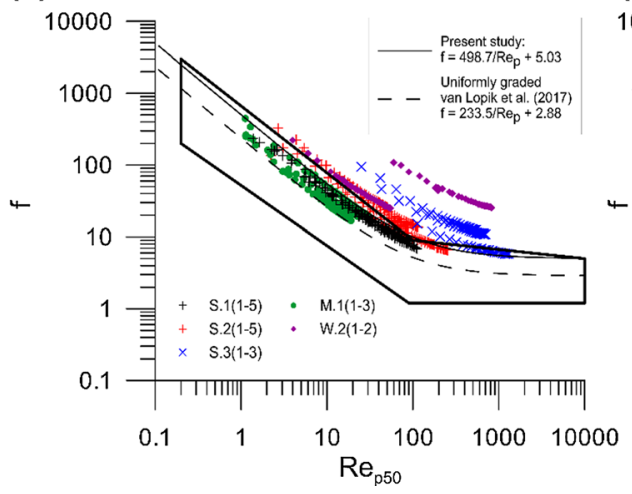

(b)

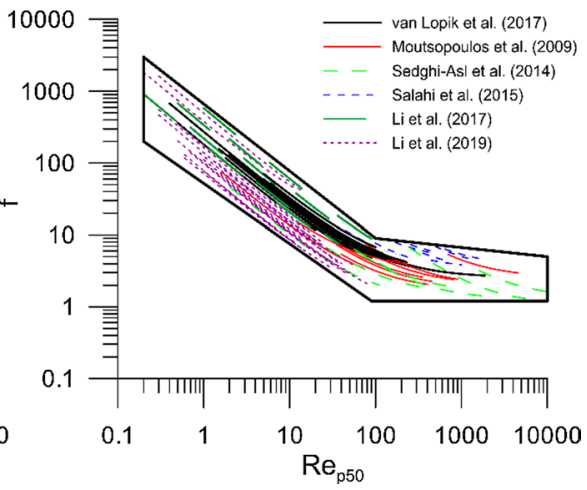

Fig. 9 a Correlation of the friction factor $f$ and the calculated $\operatorname{Re}_{p}$ using grain size $d_{50}$. The dashed correlation line is based on the dataset of 20 uniformly graded filter sands (van Lopik et al. 2017), which includes the reference samples 1-3 of the present study. The solid correlation line is based on the dataset of the present study. b The friction factor based on nonlinear flow through packed beds of different kinds of granular material using the literature dataset listed in Table 1. The studies that provide the ranges of Reynolds numbers over which the experiments were conducted are plotted. The envelope in both figures shows the upper and lower limits of the literature dataset on uniformly graded material

length (see Fig. 9a). A wide range of Ergun constants of $A$ are obtained, ranging from 254 for sample M.1 up to 6477 for sample W.2 (Table 5). Ergun constants of $B$ are in the range of 3.5 (S1.1 and S2.1) and 19.3 (W.1). Especially for the coarser granular material samples $\left(d_{50}>1.5 \mathrm{~mm}\right)$ with wider grain size distributions $\left(C_{\mathrm{u}}>5\right)$, the obtained Ergun constants are significantly higher $(A>750$ and $B>6)$ compared to uniformly graded materials.

Using the dataset from the literature (Table 1) and the average grain size $d_{50}$ of the tested porous medium, the resulting Ergun constants $A$ and $B$ are obtained from the relationship between Reynolds number and friction factor (Fig. 9b). The literature provides Reynolds number ranges over which the packed beds were tested on nonlinear flow behavior. However, the definition of the Reynolds number differs for the given studies in Table 1, and therefore we recalculated these values to equivalent $\operatorname{Re}_{p}$ values (based on the $d_{50}$ and $n$, see Eq. 3). The individual analysis of the different packed beds with granular material provides a nice overview of the range of possible Ergun constants for different kind of uniformly graded granular material (see Fig. 10).

A wide variety of $A$ and $B$ values is obtained for granular material at given average grain size $d_{50}$. Comparing the dataset of uniformly graded granular material, the Ergun constant $A$ seems to increase with increasing grain size (see Venkataraman and Rao 1998; Moutsopoulos et al. 2009; Salahi et al. 2015; Sedghi-Asl et al. 2014; Li et al. 2017; van Lopik et al. 2017). For example, estimating nonlinear flow behavior through packed beds of coarse gravel $\left(d_{50}>20 \mathrm{~mm}\right)$ requires Ergun constants $A$ that are much higher than for other granular material (values up to 4000, see Fig. 10a). The Ergun constant $B$ is in general higher than the value of 1.75 (average value $B$ of 2.8 for Ranganadha Rao and Suresh 1970; Moutsopoulos et al. 2009; Salahi et al. 2015; Li et al. 2017; van Lopik et al. 2017) (Fig. 10b). This is in line with the values suggested by 
Table 5 The resulting Ergun constants $A$ and $B$ from the present study based on the grain sizes $d_{10}, d_{30}$ and $d_{50}$

\begin{tabular}{|c|c|c|c|c|c|c|c|c|c|}
\hline \multirow[t]{2}{*}{ Sample } & \multirow[t]{2}{*}{$d_{50}[\mathrm{~mm}]$} & \multirow[t]{2}{*}{$C_{\mathrm{u}}[-]$} & \multirow[t]{2}{*}{$n[-]$} & \multicolumn{2}{|l|}{$d_{50}$} & \multicolumn{2}{|l|}{$d_{30}$} & \multicolumn{2}{|l|}{$d_{10}$} \\
\hline & & & & $A$ & $B$ & $A$ & $B$ & $A$ & $B$ \\
\hline M.1 & 0.45 & 2.60 & 0.328 & 254 & 3.92 & 137 & 2.89 & 50.2 & 1.74 \\
\hline M.2 & 0.54 & 2.82 & 0.330 & 369 & 4.11 & 193 & 2.97 & 61.3 & 1.67 \\
\hline M.3 & 0.77 & 3.86 & 0.293 & 376 & 5.80 & 152 & 3.48 & 53.3 & 2.06 \\
\hline W.1 & 1.48 & 4.84 & 0.249 & 792 & 11.1 & 209 & 5.69 & 74.8 & 3.41 \\
\hline W.2 & 9.5 & 13.05 & 0.246 & 6477 & 19.3 & 1206 & 8.34 & 64.8 & 1.93 \\
\hline S. 1 & 1.0 & 1.30 & 0.348 & 264 & 2.58 & 231 & 2.41 & 190 & 2.19 \\
\hline 1.1 & 1.0 & 2.36 & 0.346 & 386 & 3.56 & 235 & 2.77 & 85.3 & 1.67 \\
\hline 1.2 & 1.0 & 3.36 & 0.337 & 431 & 4.05 & 171 & 2.55 & 65.6 & 1.58 \\
\hline 1.3 & 1.0 & 4.09 & 0.307 & 428 & 3.97 & 107 & 1.99 & 52.5 & 1.39 \\
\hline 1.4 & 1.0 & 4.43 & 0.285 & 361 & 4.52 & 90.2 & 2.26 & 44.2 & 1.58 \\
\hline 1.5 & 1.0 & 13.64 & 0.253 & 402 & 5.15 & 77.8 & 2.27 & 43.8 & 1.70 \\
\hline S.2 & 1.5 & 1.36 & 0.358 & 259 & 2.63 & 206 & 2.35 & 154 & 2.03 \\
\hline 2.1 & 1.5 & 2.00 & 0.358 & 392 & 3.45 & 272 & 2.88 & 114 & 1.86 \\
\hline 2.2 & 1.5 & 2.88 & 0.334 & 566 & 4.71 & 237 & 3.05 & 90.6 & 1.89 \\
\hline 2.3 & 1.5 & 4.70 & 0.307 & 778 & 6.89 & 169 & 3.22 & 55.3 & 1.84 \\
\hline 2.4 & 1.5 & 6.58 & 0.265 & 629 & 6.07 & 137 & 2.83 & 44.7 & 1.62 \\
\hline 2.5 & 1.5 & 17.35 & 0.242 & 857 & 8.70 & 91.4 & 2.84 & 44.0 & 1.97 \\
\hline$S .3$ & 6.3 & 1.27 & 0.361 & 362 & 2.80 & 310 & 2.59 & 239 & 2.28 \\
\hline 3.1 & 6.3 & 3.73 & 0.324 & 1164 & 4.90 & 690 & 3.77 & 99.3 & 1.43 \\
\hline 3.2 & 6.3 & 7.35 & 0.252 & 1825 & 8.18 & 167 & 2.48 & 85.0 & 1.77 \\
\hline 3.3 & 6.3 & 12.33 & 0.227 & 2192 & 8.36 & 119 & 1.95 & 76.9 & 1.57 \\
\hline \multicolumn{4}{|c|}{ Median value (present study) } & 498.7 & 5.03 & 168.0 & 2.86 & 63.1 & 1.72 \\
\hline \multicolumn{4}{|c|}{$\begin{array}{l}\text { Uniformly graded }\left(C_{\mathrm{u}}<2.32\right) \text { (van Lopik et al. } \\
\text { 2017) }\end{array}$} & 233.5 & 2.88 & 183.8 & 2.53 & 120.3 & 2.03 \\
\hline
\end{tabular}

The samples S.1, S.2 and S.3 in italic are the reference sands obtained from dataset of van Lopik et al. (2017) (respectively, samples 7, 9 and 11 in their study)

Kovács (1981) $(B=2.4)$ for sediments, as well as the values from Engelund (1953), who stated that for smooth particles $B$ is 1.8 , while for angular particles $B$ is 3.8 .

The Ergun constants for granular materials with wider grain size distributions are notably higher compared to the dataset on uniformly graded granular material (Table 5; Fig. 10). Hence, the present dataset of graded granular material is also analyzed using the Ergun form of the friction factor (Eqs. 7, 8) while using the $d_{30}$ and $d_{10}$ as characteristic pore length (Fig. 11). For uniformly graded filter sands and gravels $\left(C_{\mathrm{u}}<2\right)$ using $d_{30}$ and $d_{10}$, the friction factors are (van Lopik et al. 2017):

$$
\begin{aligned}
& f=\frac{183.8}{\operatorname{Re}_{p 30}}+2.53 ; \quad \text { for } d_{30} \text { and } C_{u}<2 \\
& f=\frac{120.3}{\operatorname{Re}_{p 10}}+2.03 ; \quad \text { for } d_{10} \text { and } C_{u}<2
\end{aligned}
$$




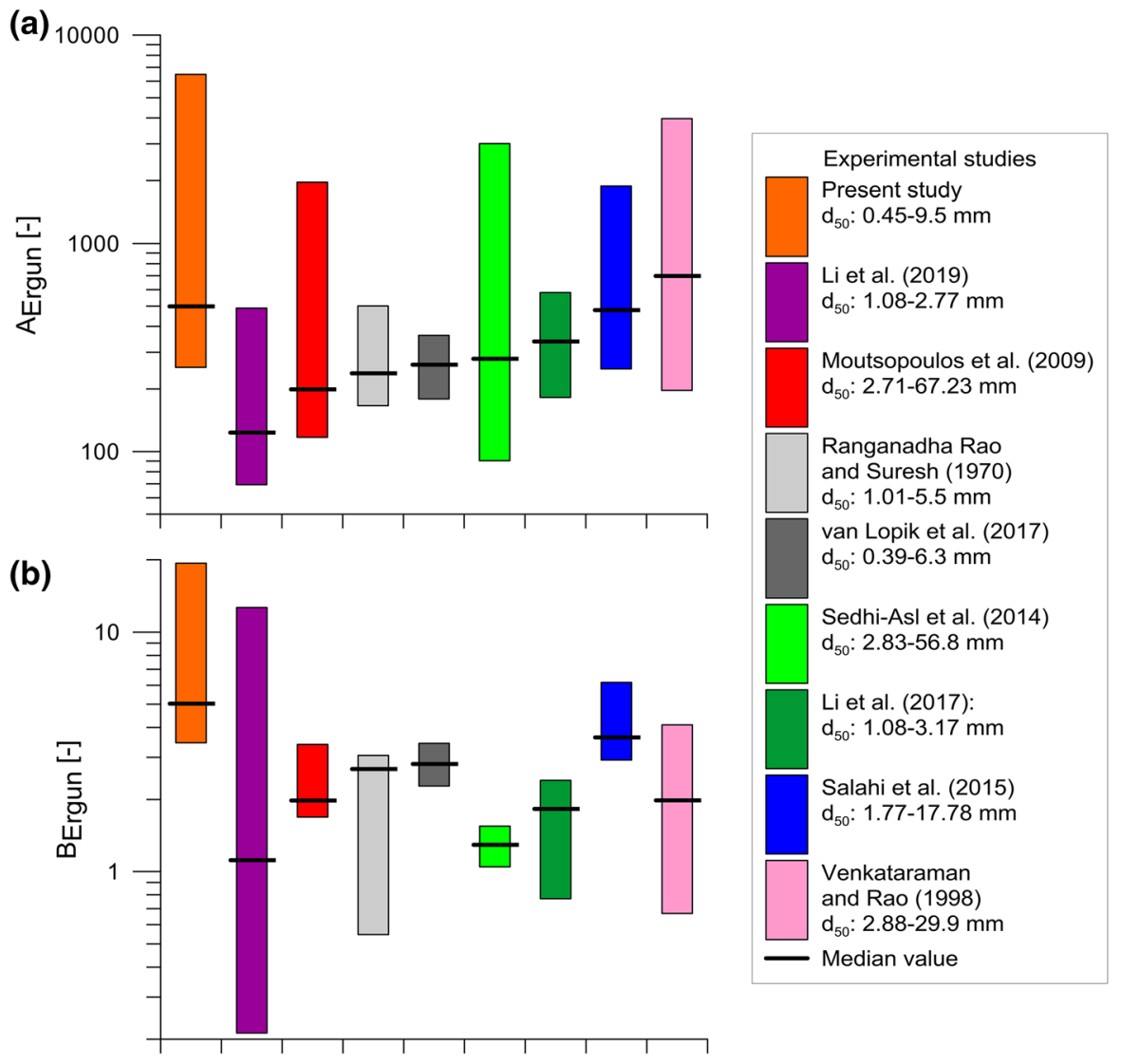

Experimental studies in literature

Fig. 10 Overview of dataset from the literature (see Table 1) of the resulting Ergun constants obtained from the provided grain sizes, porosity values and Forchheimer coefficients $a$ and $b$ in the literature for a Ergun constant $A$ and b Ergun constant $B$

While for the dataset of the present study with granular material of wider grain size distributions $\left(C_{\mathrm{u}}>2\right)$, the friction factor is:

$$
\begin{aligned}
& f=\frac{168.0}{\operatorname{Re}_{p 30}}+2.86 ; \quad \text { for } d_{30} \text { and } C u>2 \\
& f=\frac{63.1}{\operatorname{Re}_{p 10}}+1.72 ; \quad \text { for } d_{10} \text { and } C u>2
\end{aligned}
$$

Considering the entire dataset of the present study, the overall correlation between friction factor and $\operatorname{Re}_{p}$ with $d_{10}$ is good (Fig. 11b). Hence, we suggest the use of 63.1 and 1.72 for, respectively, Ergun constants $A$ and $B$, while using the $d_{10}$ as characteristic pore length for sand and gravel with wider grain size distributions. 
(a)

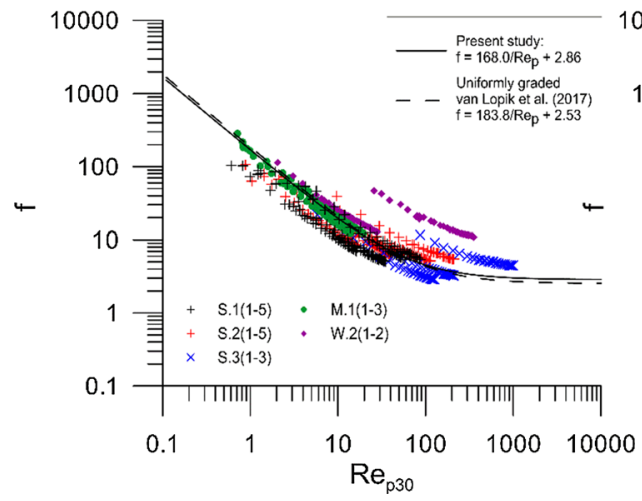

(b)

Fig. 11 a Correlation of the friction factor $f$ and the calculated $\operatorname{Re}_{p}$ with a characteristic pore length of $d_{50}$, b as well as for a characteristic pore length of $d_{50}$. The dashed correlation line is based on the dataset of 20 uniformly graded filter sands (van Lopik et al. 2017), which include the reference samples 1-3 of the present study. The solid correlation line is based on the dataset of the present study

\subsection{Correlation Forms for Forchheimer Coefficient b}

The differences between the experimentally obtained Forchheimer coefficients $b$ and the derived coefficients from empirical relationships listed in Table 3 are shown in Fig. 12. Using the correlation form of Geertsma (1974) for Forchheimer $\beta$, the estimation of the experimentally obtained values is poor (Fig. 12a). The derived Forchheimer coefficients $b$ are highly overestimated, and the scattering around the linear regression slope is high with a $R^{2}$-coefficient of 0.70 . Due to the relative importance of the porosity term $\left(n^{-5.5}\right)$ in the Geertsma (1974) equation in comparison with the other equations in Table 3, the low porosity values $(0.25<n<0.33)$ of the samples in this study results in this significant overestimation. For Janicek and Katz (1955), the fit is reasonable with a $R^{2}$-coefficient of, 0.76 (Fig. 12b).

The scattering around the linear regression slope is significantly reduced for the empirical relationships that included the tortuosity model of Mota et al. (2001) for mixed particle beds (Fig. 12c). Combining this tortuosity model with the correlation forms of Liu et al. (1995) and Thauvin and Mohanty (1998), the $R^{2}$-coefficients are, respectively, 0.86 and 0.88 . In order to obtain a better correlation with the experimental data, the coefficients in these correlation forms are modified (Fig. 12d). The modified correlation form of Liu et al. (1995) is:

$$
\beta=3.1 * 10^{6} \frac{\tau}{k n}=3.1 * 10^{6} k^{-1} n^{-1.4} \quad \text { with } R^{2}=0.86
$$

where $k[\mathrm{mD}]$ is the intrinsic permeability.

The modified correlation form of Thauvin and Mohanty (1998) is:

$$
\beta=2.0 * 10^{3} k^{-0.98} n^{-0.29} \tau^{3.35}=2 * 10^{3} k^{-0.98} n^{-1.63} \quad \text { with } R^{2}=0.88
$$

where $k[\mathrm{D}]$ is the intrinsic permeability. 
(a)

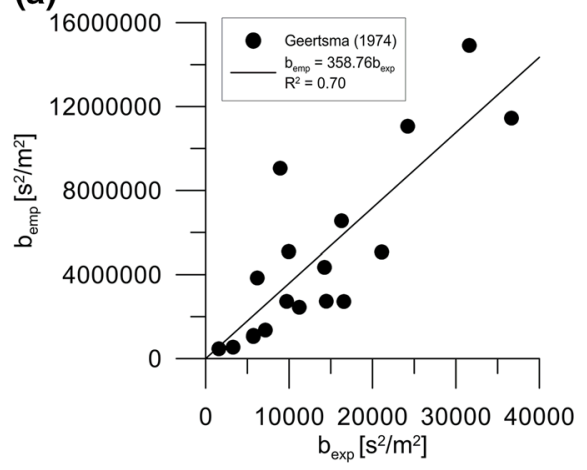

(c)

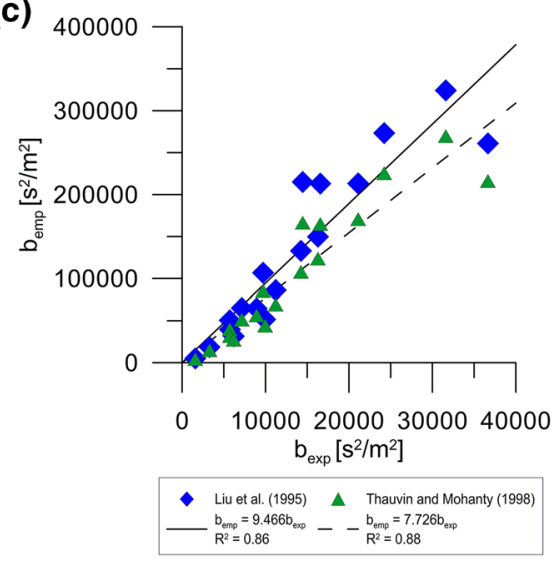

(b)

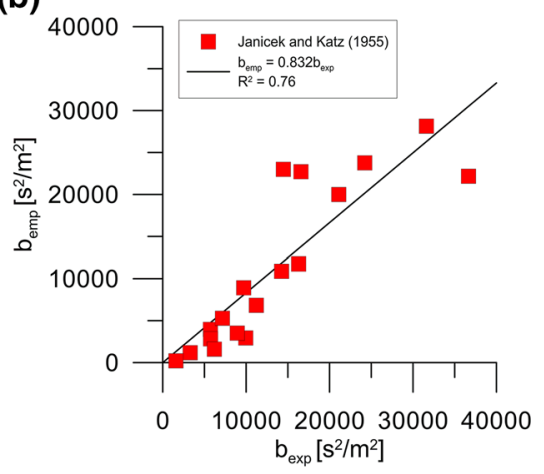

(d)

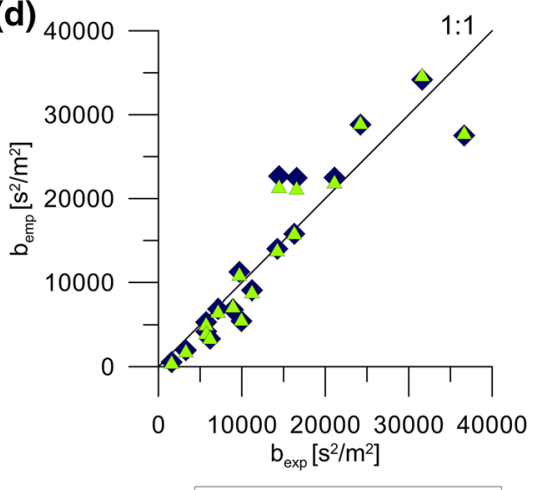

- Modified Liu et al. (1995) Modified Thauvin and Mohanty (1998)

Fig. 12 Linear regression analysis of the Forchheimer coefficient $b$ using the correlation form of a Geertsma (1974), b Janicek and Katz (1955), c Liu et al. (1995) and Thauvin and Mohanty (1998) and d the modified correlation forms Eqs. (17)-(18)

\section{Discussion}

Nonlinear flow behavior in porous media is controlled by the microscale processes at the fluid-solid interfaces of the pore structures and pore geometry (e.g., Dybbs and Edward 1984; Hassanizadeh and Gray 1987; Ma and Ruth 1993; Panfilov and Fourar 2006). Moreover, these microscale processes differ over the different Reynold number ranges. Commonly, post-Darcian nonlinear flow is separated in two flow regimes. These are the nonlinear laminar flow regime (also known as Forchheimer regime or transition flow regime) and the fully turbulent flow regime (Andersen and Burcharth 1995; Lage 1998; Houben 2015). This is done by flow visualization studies in porous media that determined the onset of turbulent flow (e.g., Dybbs and Edwards 1984; Seguin et al. 1998), as well as analysis of macroscale flow experiments on packed beds (e.g., Venkataraman and Rao 1998; SedghiAsl and Rahimi 2011; Bağci et al. 2014). This transition between the different flow regimes in the post-Darcian flow regime is hard to define for natural irregular and graded granular materials such as used in this study (Andersen and Burcharth 1995). 
In practice, the traditional Ergun-type formulations are still widely used to provide estimates for the Forchheimer coefficients $a$ and $b$ (Eq. 3), since these are based on the easy measurable parameters such as a particle diameter for the characteristic pore length and the porosity. Previous studies have shown that besides the particle diameter and porosity, also the particle shape and packing arrangement has a significant impact on nonlinear flow behavior (e.g., Engelund 1953; Allen et al. 2013; Salahi et al. 2015). Experimental studies on nonlinear flow behavior on cubic arrays of smooth glass spheres show that the flow resistance is drastically lower compared to granular material (Huang et al. 2013). This study showed that the Ergun constants provided by Irmay (1964) with values $A$ and $B$ of, respectively, 180 and 0.6 suffice to predict the experimental data. The cubic arrangement of the smooth spheres allowed for the use of low $B$ values of 0.6. However, for randomly packed beds of smooth particles, resulting in non-cubic arrangements, the resulting Ergun constants are much higher. Even for randomly packed beds of smooth spheres a wide variety of Ergun constants is obtained in the literature due to the varying pore structures (e.g., MacDonald et al. 1979; Fand et al. 1987; Bagci et al. 2014; Erdim et al. 2015). For angular shaped particles, which usually vary in shape for each granular particle, it is even harder to obtain one single specific characteristic pore length to account for the entire pore geometry of the packed bed of granular material. Moreover, during packing of asymmetric elongated particles, no isotropic packing arrangement will be obtained, since the particles tend to align during packing in such way that the larger areas are parallel to the bottom of the outlet (Allen et al. 2013). Packing the grains in such way that they align with the flow direction, significant reduction in flow resistance is observed. In the present study slightly elongated subangular-subrounded sands were used ("Appendix 2"), and anisotropy in packed beds of the mixed granular material will have an impact on the flow resistance. However, the differences in grain shape between the used sands in this study are very small ("Appendix 2") and hence, the variations in the flow resistance are mainly due to differences in the pore geometry by different grain sizes and packing arrangement of the non-uniformly graded granular material.

The present study shows that nonlinear flow behavior through packed beds of granular material with wide grain size distributions $\left(C_{\mathrm{u}}>2\right)$ deviates drastically from flow through uniformly graded material (Figs. 9, 10). The packing arrangements of such granular material differ from uniformly graded material, which is reflected by the decreased porosities of the tested granular material (Fig. 2). The heterogeneity of the packed bed with a wide grain size distribution results in increased complexity of the pore structure, smaller pore spaces and hence, higher tortuosity values. The use of the correlation forms for the nonlinear Forchheimer coefficient $\beta$ of Liu et al. (1995) and Thauvin and Mohanty (1998) in combination with the tortuosity model of Mota et al. (2001) for mixed spherical particles beds resulted in a reasonable prediction of the experimental dataset. However, the actual values for tortuosity in both Darcian and non-Darcian flow regimes are difficult to measure for a given pore structure of the packed bed. Therefore, one heavily relies on the different empirical relationships for tortuosity provided in the literature (e.g., Ghanbarian et al. 2013). 


\section{Conclusions}

Nonlinear flow behavior through packed beds of 5 different types of natural sand and gravel from unconsolidated aquifers, as well as 13 different composite mixtures of uniformly graded filter sands at different grain size distributions and porosity values, is investigated. This broad set provides data on the hydraulic characteristics for sand and gravel types with $C_{\mathrm{u}}$ values of $2.00-17.5$ and porosity values of $0.23-0.36$. The comparison of the dataset of the present study on sand and gravel with wide grain size distributions $\left(C_{\mathrm{u}}>2\right)$ with datasets in the literature on uniformly graded sand and gravel $\left(C_{\mathrm{u}}<2\right)$, shows that the gradation has a significant effect on nonlinear flow behavior. For graded gravels $\left(d_{50}=6.3 \mathrm{~mm}\right.$, $C_{\mathrm{u}}=12.3$ ), Forchheimer coefficients $a$ and $b$ are increased by a factor of 36 and 15 , respectively, with respect to uniformly graded gravel $\left(d_{50}=6.3 \mathrm{~mm}, C_{\mathrm{u}}=1.27\right)$.

Considering the Ergun relationship for empirical correlation of the experimental dataset while using the average grain size $d_{50}$, a wide range of Ergun constants $A$ and $B$ is obtained with values of, respectively, 233.5 and 2.88 for uniformly graded filter sands up to values of 2192 and 8.36 for poorly gap-graded gravel $\left(C_{\mathrm{u}}=12.33\right)$. In order to estimate the Forchheimer coefficients of granular material with wide grain size distributions $\left(C_{\mathrm{u}}>2\right)$, the $d_{10}$ should be used as characteristic pore length with the Ergun constants of $A$ and $B$ of 63.1 and 1.72 , respectively.

Moreover, for granular material with wider grain size distributions $\left(C_{\mathrm{u}}\right.$ values of 3.86-17.35) and low porosities $(n<0.30)$, the Forchheimer coefficient $b$ for a given coefficient $a$ is significantly higher than for more uniformly graded granular material. Hence, the quadratic term in the Forchheimer that accounts for increase in nonlinear flow resistance by additional energy dissipation is higher for such granular material.

Acknowledgements This work was supported by the foundations STW (Foundation for Technical Sciences) and O2DIT (Foundation for Research and Development of Sustainable Infiltration Techniques). The authors thank Georg Houben from the Bundesanstalt für Geowissenschaften und Rohstoffe for commenting on this manuscript and providing the grain shape analysis, Tony Valkering and Theo van Velzen (from dewatering company Theo van Velzen) for constructing the experimental setup and Peter de Vet (from dewatering company P. J. de Vet \& Zonen) for optimizing this setup. Moreover, we thank Sjaak van Lanen (from P. J. de Vet \& Zonen) for providing the natural sand samples from the Wyenhütte fieldsite and Fugro NL B.V. for providing the samples from the Münsterlaan fieldsite.

Open Access This article is licensed under a Creative Commons Attribution 4.0 International License, which permits use, sharing, adaptation, distribution and reproduction in any medium or format, as long as you give appropriate credit to the original author(s) and the source, provide a link to the Creative Commons licence, and indicate if changes were made. The images or other third party material in this article are included in the article's Creative Commons licence, unless indicated otherwise in a credit line to the material. If material is not included in the article's Creative Commons licence and your intended use is not permitted by statutory regulation or exceeds the permitted use, you will need to obtain permission directly from the copyright holder. To view a copy of this licence, visit http://creativecommons.org/licenses/by/4.0/.

\section{Appendix 1: Composition of the Artificially Mixed Filter Sands}

See Table 6. 


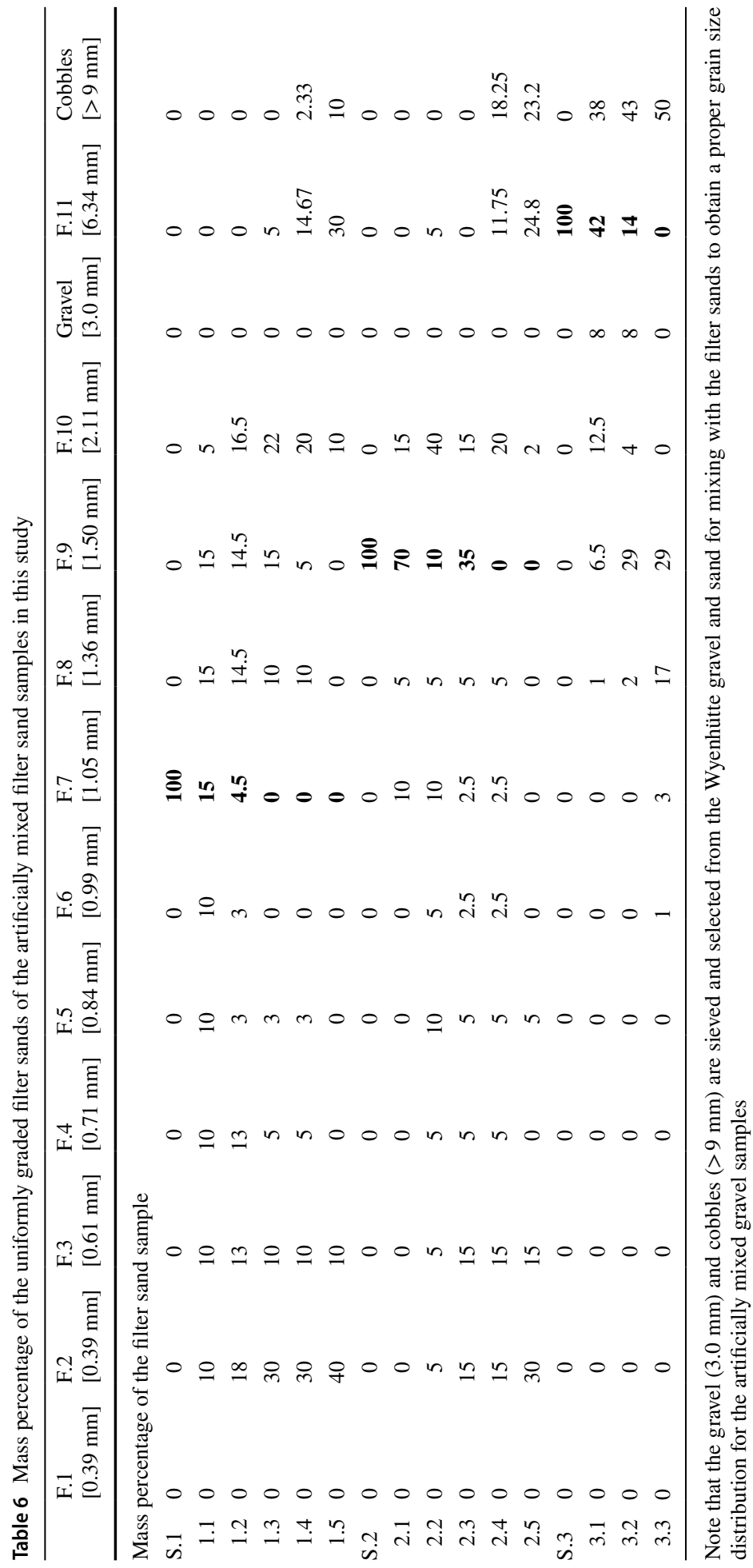




\section{Appendix 2: Grain Shape Analysis}

The grain shape properties of the filter sands that are used for the artificially mixed filter sands (see "Appendix 1"), as well as the natural sands M.1 and W.1 are determined with the CAMSIZER ${ }^{\circledR}$ P4 (Retsch, Germany). The use of the Camsizer imaging techniques enables to detect the various dimensions of irregularly shaped particles by means of the sphericity $\left(S^{\mathrm{Kr}}\right)$ and roundness $\left(R^{\mathrm{Kr}}\right)$ based on the Krumbein scale (Krumbein and Sloss 1963), sphericity $\left(S^{Q P}\right)$, symmetry (symm), convexity $\left(C_{x}\right)$, and elongation $(e)$ (e.g., Altuhafi et al. 2013):

$$
S^{Q P}=\frac{\sqrt{4 \pi A_{\mathrm{s}}}}{P}
$$

where $A_{\mathrm{s}}\left[\mathrm{m}^{2}\right]$ is the surface area, and $P[\mathrm{~m}]$ is the perimeter of the sphere.

$$
\operatorname{symm}=\frac{1}{2}\left[1+\min \frac{r_{1}}{r_{2}}\right]
$$

where $r_{1}$ und $r_{2}[\mathrm{~m}]$ are the distances from the center of the grain to the outer borders in the measuring direction. For asymmetric particles Symm is $<1$.

$$
C_{x}=\sqrt{\frac{A_{\text {real }}}{A_{\text {conv }}}}
$$

where $A_{\text {real }}\left[\mathrm{m}^{2}\right]$ is the real area of the particle projection and $A_{\text {conv }}\left[\mathrm{m}^{2}\right]$ is the convex area of particle projection.

$$
e=\frac{L}{W}
$$

where $L[\mathrm{~m}]$ is the maximum grain diameter and the $W[\mathrm{~m}]$ is minimum grain diameter.

The grain shape analysis in Table 7 shows that the grain characteristics of the filter sands and natural sands are similar and the granular material can be classified as subangular-subrounded sand.

Table 7 Grain shape properties

\begin{tabular}{|c|c|c|c|c|c|c|}
\hline & $S^{\mathrm{QP}}$ & Symm & $e$ & $C_{x}$ & $S^{\mathrm{Kr}}$ & $* R^{\mathrm{Kr}}$ \\
\hline \multicolumn{7}{|c|}{ Filter sand used for artificially mixed sands } \\
\hline F.2 & 0.79 & 0.90 & 1.35 & 0.99 & 0.75 & 0.54 \\
\hline F.3 & 0.80 & 0.90 & 1.34 & 0.99 & 0.76 & 0.55 \\
\hline F.4 & 0.80 & 0.90 & 1.34 & 0.99 & 0.75 & 0.54 \\
\hline F.5 & 0.80 & 0.90 & 1.35 & 0.99 & 0.75 & 0.52 \\
\hline F.6 & 0.80 & 0.90 & 1.35 & 0.99 & 0.75 & 0.54 \\
\hline F.7 & 0.80 & 0.90 & 1.35 & 0.99 & 0.75 & 0.52 \\
\hline F.8 & 0.79 & 0.90 & 1.38 & 0.99 & 0.73 & 0.52 \\
\hline F.9 & 0.79 & 0.90 & 1.38 & 0.99 & 0.73 & 0.52 \\
\hline \multicolumn{7}{|c|}{ Natural sand } \\
\hline M.1 & 0.79 & 0.90 & 1.35 & 0.99 & 0.75 & 0.54 \\
\hline W.1 & 0.76 & 0.90 & 1.39 & 0.99 & 0.73 & 0.48 \\
\hline
\end{tabular}
of the filter sands with a grain size smaller than $2.0 \mathrm{~mm}$ and the natural sand M.1 and W.1
*Note that $R^{\mathrm{Kr}}$ is calculated on the grain size range of $0.3-2.0 \mathrm{~mm}$ 


\section{References}

Adler, P.M., Malevich, A.E., Mityushev, V.V.: Nonlinear correction to Darcy's law for channels with wavy walls. Acta Mech. 224, 1823-1848 (2013)

Allen, K.G., von Bäckström, T.W., Kröger, D.G.: Packed bed pressure drop dependence on particle shape, size distribution, packing arrangement and roughness. Powder Technol. 246, 590-600 (2013)

Altuhafi, F., O'Sullivan, C., Cavarretta, I.: Analysis of an image-based method to quantify the size and shape of sand particles. J. Geotech. Geoenviron. Eng. 139(8), 1290-1307 (2013)

Andersen, O.H., Burcharth, H.F.: On the one-dimensional steady and unsteady porous flow equation. Coast. Eng. 24, 233-257 (1995)

Bağci, Ö., Dukhan, N., Özdemir, M.: Flow regimes in packed beds of spheres from pre-Darcy to turbulent. Transp. Porous Med. 104(3), 501-520 (2014)

Banerjee, A., Pasupuleti, S., Singh, M.K., Kumar, G.N.P.: A study on the Wilkins and Forchheimer equations used in coarse granular media flow. Acta Geophys. 66(1), 81-91 (2018)

Basak, P.: Analytical solutions for two-regime well flow problems. J. Hydrol. 38(1-2), 147-159 (1978)

Bear, J.: Dynamics of Fluids in Porous Media. Dover, New York (1972)

Bordier, C., Zimmer, D.: Drainage equations and non-Darcian modeling in coarse porous media or geosynthetic materials. J. Hydrol. 228(3-4), 174-187 (2000)

Carman, P.C.: Fluid flow through granular beds. Trans. Inst. Chem. Eng. 15, 150-156 (1937)

Chen, Z., Lyons, S.L., Qin, G.: Derivation of the Forchheimer law via homogenization. Transp. Porous Med. 44(2), 325-335 (2001)

Comiti, J., Saribi, N.E., Montillet, A.: Experimental characterization of flow regimes in various porous media-3: limit of Darcy's or creeping flow regime for Newtonian and purely viscous non-Newtonian fluids. Chem. Eng. Sci. 55(15), 3057-3061 (2000)

Dan, H.-C., He, L.-H., Xu, B.: Experimental investigation on non-Darcian flow in unbound graded aggregate material of highway pavement. Transp. Porous Med. 112(1), 189-206 (2016)

Darcy, H.: Les fontaines publiques de la ville de Dyon. Exposition et application des principes à suivre et des formules à employer dans les questions de distribution d'eau. Ouvrage terminé par un appendice relatif aux fournitures d'eau de plusieurs villes au filtrage des eaux et à la fabrication des tuyaux de fonte, de plomb, de tole et de bitume. Dalmont, Paris (1856). [With 2nd volume: Atlas]

Das, B.M.: Advanced Soil Mechanics, 3rd edn. Taylor \& Francis, London (2008)

Du Plessis, J.P.: Analytical quantification of coefficients in the Ergun equation for fluid friction in a packed bed. Transp. Porous Med. 16(2), 189-207 (1994)

Dybbs, A., Edwards, R.V.: A new look at porous media fluid mechanics: Darcy to turbulent. In: Bear J., Corapcioglu Y. (eds.) Fundamentals of Transport Phenomena in Porous Media: Proceedings of the NATO Advanced Study Institute on Mechanics of Fluids in Porous Media, Newark, Delaware, U.S.A., July 18-27, 1982, pp. 199-256. Nijhoff, Dordrecht (1984)

Engelund, F.A.: On the Laminar and Turbulent Flow of Groundwater Through Homogeneous Sands. Akademit for de Tekniske Videnskaber, København (1953). [Transactions of the Danish Academy of Technical Sciences, A.T.S. 1953, 3; Technical University of Denmark. Hydraulic Laboratories/ Bulletin 4]

Erdim, E., Akgirkay, Ö., Demir, I.: A revisit of pressure drop-flow rate correlations for packed beds of spheres. Powder Technol. 283, 488-504 (2015)

Ergun, S.: Fluid flow through packed columns. Chem. Eng. Prog. 48(2), 89-95 (1952)

Fand, R.M., Kim, B.Y.K., Lam, A.C.C., Phan, R.T.: Resistance to the flow of fluids through simple and complex porous media whose matrices are composed of randomly packed spheres. J. Fluids Eng. 109(3), 268-273 (1987)

Ferdos, F., Wörman, A., Ekström, I.: Hydraulic conductivity of coarse rockfill used in hydraulic structures. Transp. Porous Med. 108(2), 367-391 (2015)

Forchheimer, P.H.: Wasserbewegung durch Boden. Z. Ver. Deutsch. Ing. 50, 1781-1788 (1901)

Geertsma, J.: Estimating the coefficient of inertial resistance in fluid flow through porous media. Soc. Pet. Eng. J. 14(5), 445-450 (1974)

Ghanbarian, B., Hunt, A.G., Ewing, R.P., Sahimi, M.: Tortuosity in porous media: a critical review. Soil Sci. Soc. Am. J. 77, 1461-1477 (2013)

Greenly, B.T., Joy, D.M.: One-dimensional finite-element model for high flow velocities in porous media. J. Geotech. Eng. 122(10), 786-796 (1996)

Guo, P., Stolle, D., Guo, S.X.: An equivalent spherical particle system to describe characteristics of flow in a dense packing of non-spherical particles. Transp. Porous Med. 129(1), 253-280 (2019) 
Hassanizadeh, S.M., Gray, W.G.: High velocity flow in porous media. Transp. Porous Med. 2(6), 521531 (1987)

Houben, G.J.: Review: hydraulics of water wells-flow laws and influence of geometry. Hydrogeol. J. 23(8), 1633-1657 (2015)

Houben, G.J., Wachenhausen, J., Morel, C.R.G.: Effects of ageing on the hydraulics of water wells and the influence of non-Darcy flow. Hydrogeol. J. 26(4), 1285-1294 (2018)

Huang, K., Wan, J.W., Chen, C.X., He, L.Q., Mei, W.B., Zhang, M.Y.: Experimental investigation on water flow in cubic arrays of spheres. J. Hydrol. 492, 61-68 (2013)

Irmay, S.: Theoretical models of flow through porous media. In: Proceedings International Symposium on Transport of Water in Porous Media, vol. 29, pp. 37-43. Paris (1964)

Janicek, J., Katz, D.: Applications of unsteady state gas flow calculations. In: Katz, D.L., Cornell, D. (eds.) Flow of Natural Gas from Reservoirs. Research Conference, University of Michigan, June 30-July 1, 1955, 44 pp. College of Engineering, University of Michigan, Michigan, Ann Arbor, MI (1955)

Kovács, G.: Seepage Hydraulics. Elsevier, Amsterdam (1981)

Krumbein, W.C., Sloss, L.L.: Stratigraphy and Sedimentation, 2nd edn. Freeman, San Francisco (1963)

Lage, J.L.: The fundamental theory of flow through permeable media from Darcy to turbulence. In: Ingham, D.B., Pop, I. (eds.) Transport Phenomena in Porous Media, pp. 1-30. Pergamon, New York (1998)

Li, Z., Wan, J., Huang, K., Chang, W., He, Y.: Effects of particle diameter on flow characteristics in sand columns. Int. J. Heat Mass Transf. 104, 533-536 (2017)

Li, Z., Wan, J., Zhan, H., Cheng, X., Chang, W., Huang, K.: Particle size distribution on Forchheimer flow and transition of flow regimes in porous media. J. Hydrol. 574, 1-11 (2019)

Liu, X., Civan, F., Evans, R.D.: Correlation of the non-Darcy flow coefficient. J. Can. Pet. Technol. 34(10), 50-54 (1995)

Ma, H., Ruth, D.W.: The microscopic analysis of high Forchheimer number flow in porous media. Transp. Porous Med. 13(2), 139-160 (1993)

Macdonald, I.F., El-Sayed, M.S., Mow, K., Dullien, F.A.L.: Flow through porous media-the Ergun equation revisited. Ind. Eng. Chem. Fundam. 18(3), 199-208 (1979)

Mathias, S.A., Todman, L.C.: Step-drawdown tests and the Forchheimer equation. Water Resour. Res. 46(7), W07514 (2010)

Mathias, S.A., Moutsopoulos, K.N.: Approximate solutions for Forchheimer flow during water injection and water production in an unconfined aquifer. J. Hydrol. 538, 13-21 (2016)

McElwee, C.D., Zenner, M.A.: A nonlinear model for analysis of slug-test data. Water Resour. Res. 34(1), 55-66 (1998)

Moutsopoulos, K.N., Tsihrintzis, V.A.: Approximate analytical solutions of the Forchheimer equation. J. Hydrol. 309(1-4), 93-103 (2005)

Moutsopoulos, K.N.: One-dimensional unsteady inertial flow in phreatic aquifers induced by a sudden change of the boundary head. Transp. Porous Med. 70(1), 97-125 (2007)

Moutsopoulos, K.N., Papaspyros, I.N.E., Tsihrintzis, V.A.: Experimental investigation of inertial flow processes in porous media. J. Hydrol. 374(3-4), 242-254 (2009)

Mota, M., Teixeira, J.A., Bowen, W.R., Yelshin, A.: Binary spherical particle mixed beds: porosity and permeability relationship measurement. Trans. Filtr. Soc. 1(4), 101-106 (2001)

Nield, D.A.: Resolution of a paradox involving viscous dissipation and nonlinear drag in a porous medium. Transp. Porous Med. 41(3), 349-357 (2000)

Panfilov, M., Fourar, M.: Physical splitting of nonlinear effects in high-velocity stable flow through porous media. Adv. Water Resour. 29(1), 30-41 (2006)

Ranganadha Rao, R.P., Suresh, C.: Discussion of 'non-linear flow in porous media', by N Ahmed and DK Sunada. J. Hydraul. Div. Proc. ASCE 96(8), 1732-1734 (1970)

Rietdijk, J., Schenkeveld, F.M., Schaminée, P.E.L., Bezuijen A.: The drizzle method for sand sample preparation. In: Laue, J., Springman, S., Seward, L. (eds.) Proceedings of 6th International Conference on Physical Modelling, pp. 267-272 (2010)

Salahi, M.-B., Sedghi-Asl, M., Parvizi, M.: Nonlinear flow through a packed-column experiment. J. Hydrol. Eng. 20(9) (2015)

Sedghi-Asl, M., Rahimi, H.: Adoption of Manning's equation to 1D non-Darcy flow problems. J. Hydraul. Res. 49(6), 814-817 (2011)

Sedghi-Asl, M., Rahimi, H., Salehi, R.: Non-Darcy flow of water through a packed column test. Transp. Porous Med. 101(2), 215-227 (2014)

Seguin, D., Montillet, A., Comiti, J., Huet, F.: Experimental characterization of flow regimes in various porous media-2: transition to turbulent regime. Chem. Eng. Sci. 53(22), 3897-3909 (1998) 
Sidiropoulou, M.G., Moutsopoulos, K.N., Tsihrintzis, V.A.: Determination of Forchheimer equation coefficients a and b. Hydrol. Proc. 21(4), 534-554 (2007)

Skjetne, E., Auriault, J.L.: High velocity laminar and turbulent flow in porous media. Transp. Porous Med. 36(2), 131-147 (1999)

Thauvin, F., Mohanty, K.K.: Network modeling of non-Darcy flow through porous media. Transp. Porous Med. 31(1), 19-37 (1998)

van Lopik, J.H., Snoeijers, R., van Dooren, T.C.G.W., Raoof, A., Schotting, R.J.: The effect of grain size distribution on nonlinear flow behavior in sandy porous media. Transp. Porous Med. 120(1), 37-66 (2017)

Venkataraman, P., Rao, P.R.M.: Darcian, transitional, and turbulent flow through porous media. J. Hydraul. Eng. ASCE Hydraul. Div. 124(8), 840-846 (1998)

Wang, L., Li, Y., Zhao, G., Chen, N., Xu, Y.: Experimental investigation of flow characteristics in porous media at low Reynolds numbers $(\mathrm{Re} \rightarrow 0)$ under different constant hydraulic heads. Water 11, 2317 (2019)

Wen, Z., Liu, K., Chen, X.: Approximate analytical solution for non-Darcian flow toward a partially penetrating well in a confining aquifer. J. Hydrol. 498, 124-131 (2013)

Whitaker, S.: The Forchheimer equation: a theoretical development. Transp. Porous Med. 25(1), 27-61 (1996)

Yamada, H., Nakamura, F., Watanabe, Y., Murakami, M., Nogami, T.: Measuring hydraulic permeability in a stream bed using the packer test. Hydrol. Process. 19(13), 2507-2524 (2005)

Yeh, H.D., Chang, Y.C.: Recent advances in modeling of well hydraulics. Adv. Water Resour. 51, $27-51$ (2013)

Publisher's Note Springer Nature remains neutral with regard to jurisdictional claims in published maps and institutional affiliations. 